\title{
Ligand stimulation induces clathrin- and Rab5- dependent downregulation of the kinase-dead EphB6 receptor preceded by the disruption of EphB6-Hsp90 interaction
}

Odette Allonby $^{a}$, Amr M. El Zawily ${ }^{a}$, Tanya Freywald ${ }^{a}$, Darrell D. Mousseau ${ }^{b, c}$, Jennifer Chlan ${ }^{b, d}$, Deborah Anderson $^{\mathrm{e}, \mathrm{f}}$, Alexandre Benmerah ${ }^{\mathrm{g}, \mathrm{h}}$, Vishaldeep Sidhu', Mohan Babu', John DeCoteau ${ }^{\mathrm{a}}$ and $^{\mathrm{i}}$ Andrew Freywald ${ }^{\mathrm{a}, \mathrm{e}}$

a Department of Pathology, College of Medicine, University of Saskatchewan, Saskatoon, SK, S7N 5E5, Canada,

${ }^{\mathrm{b}}$ Department of Psychiatry, College of Medicine, University of Saskatchewan, Saskatoon, SK, S7N 5E5, Canada,

${ }^{\mathrm{c}}$ Department of Physiology, College of Medicine, University of Saskatchewan, Saskatoon, SK, S7N 5E5, Canada,

${ }^{\mathrm{d}}$ Department of Anatomy and Cell Biology, College of Medicine, University of Saskatchewan, Saskatoon, SK, S7N 5E5, Canada

${ }^{\mathrm{e}}$ Department of Biochemistry, College of Medicine, University of Saskatchewan, Saskatoon, SK, S7N 5E5, Canada

${ }^{f}$ Cancer Research Unit, Saskatchewan Cancer Agency and the University of Saskatchewan, Saskatoon, SK, S7N 5E5, Canada

IINSERM, U1163, Laboratory of Inherited Kidney Diseases 75015, Paris, France

huniversité Paris Descartes - Sorbonne Paris Cité, Institut Imagine, 75015, Paris, France

'Department of Biochemistry, Research and Innovation Centre, University of Regina, Regina, SK, S4S 0A2, Canada

* Corresponding author: Andrew Freywald, 4D01.9 107 Wiggins Rd, University of Saskatchewan, Saskatoon, SK, S7N 5E5, Canada, phone: +1(306) 966-5248, fax: +1(306) 655-0235, email: andrew.freywald@usask.ca

Email: odette.allonby@usask.ca, amr.elzawily@usask.ca, tanya.freywald@usask.ca, darrell.mousseau@usask.ca, jen.chlan@usask.ca, deborah.anderson@saskcancer.ca, alexandre.benmerah@inserm.fr, vishaldeep.sidhu@uregina.ca, mohan.babu@uregina.ca, and john.decoteau@usask.ca 


\section{Abstract}

Ligand-induced internalisation and subsequent downregulation of receptor tyrosine kinases (RTKs) serve to determine biological outputs of their signalling. Intrinsically kinase-deficient RTKs control a variety of biological responses, however, the mechanism of their downregulation is not well understood and its analysis is focused exclusively on the ErbB3 receptor.

The Eph group of RTKs is represented by the EphA and EphB subclasses. Each bears one kinase-inactive member, EphA10 and EphB6, respectively, suggesting an important role for these molecules in the Eph signalling network. While EphB6 effects on cell behaviour have been assessed, the mechanism of its downregulation remains elusive.

Our work reveals that EphB6 and its kinase-active relative, and signaling partner, EphB4, are downregulated in a similar manner in response to their common ligand, ephrin-B2. Following stimulation, both receptors are internalised through clathrin-coated pits and are degraded in lysosomes. Their targeting for lysosomal degradation relies on the activity of an early endosome regulator, the Rab5 GTPase, as this process is inhibited in the presence of a Rab5 dominant-negative mutant. EphB6 also interacts with the Hsp90 chaperone and EphB6 downregulation is preceded by their rapid dissociation. Moreover, the inhibition of Hsp90 results in EphB6 degradation, mimicking its ligand-induced downregulation. These processes appear to rely on overlapping mechanisms, since Hsp90 inhibition does not significantly enhance ligand-induced EphB6 elimination.

Taken together, our observations define a novel mechanism for intrinsically kinase-deficient RTK downregulation and support an intriguing model, where Hsp90 dissociation acts as a trigger for ligand-induced receptor removal.

Key words: EphB6, EphB4, Hsp90, internalisation, receptor tyrosine kinase, downregulation 


\section{Introduction}

Molecular mechanisms controlling receptor downregulation that is assured by its internalisation, trafficking and eventually, proteolytic degradation, actively modulate responses cell-surface receptors generate following ligand stimulation, and have a profound influence on cell behaviour [1]. Ligand-induced receptor internalisation is a multipurpose process that gates routes towards both receptor degradation and signal abrogation, as well as to efficient activation of certain signalling pathways, including the Ras-MAPK cascade [2]. In agreement, imbalanced downregulation of a number of receptor tyrosine kinases (RTKs) through stimulation-triggered internalisation and degradation, has been linked to oncogenic transformation [1, 3, 4]. Thus, disruption of Met receptor degradation, following activation by its ligand, HGF, leads to a sustained activation of the Ras-MAP kinase pathway and oncogenic transformation in non-small-cell lung cancer [5]. Colony-stimulating factor-1 receptor mutations, which impair its internalisation and degradation, have been linked to myelodysplasia and acute myeloid leukemia [6], and the mitogenic capacity of c-Kit receptor signalling is greatly enhanced in a mutant lacking a docking site for c-Cbl, a welldescribed regulator of receptor downregulation [7].

A striking example of the power of naturally inefficient RTK downregulation is presented by a member of the EGF receptor (EGFR) group (conventionally called ErbB group), ErbB2. The high potency of ErbB2 receptor action is in part, assured by its ineffective internalisation and degradation, and by its ability to slow down ligand-induced downregulation of other ErbB receptors in heterodimers [8-11]. This results in highly active and robust signalling, which in pathological situations, drives malignant cell behaviour in a variety of tumours, including those of breast, ovarian, gastric, and lung origins [12, 13].The oncogenic potential that stems from inefficient ErbB2 downregulation, and from its ability to modify the internalisation and degradation of its signalling partners gives a strong indication of the biological importance of modulating the balance in these processes. Although the RTK family contains five intrinsically kinase-inactive members [14-18] and, while some of these molecules are known to have important biological functions $[13,19,20]$, our current understanding of the mechanism of their ligand-induced downregulation is incomplete and is limited to reports focused exclusively on another member of the EGFR group, the ErbB3 receptor. Furthermore, even the mechanism of ErbB3 downregulation is far from being completely understood, as this receptor appears to behave in an inconsistent fashion, demonstrating both internalisation- and downregulationdeficiency, or efficient downregulation in various models [21-26].

Interestingly, two of five known kinase-deficient RTKs belong to the Eph group of receptors $[16,17,27]$. The eph gene was initially identified in the late 1980's by Hirai et al. during a screen of the human genome for tyrosine kinase domains [28]. Today, sixteen Eph receptor tyrosine kinases have been described, including ten EphA (EphA1- 
EphA10) and six EphB receptors (EphB1-EphB6), and most of them, with the exception of EphA9 and EphB5, are expressed in mammals. Stimulation of Eph receptors with their ligands, ephrins, triggers receptor dimerization or oligomerization, auto-phosphorylation, and the initiation of cytoplasmic signalling [29]. Through their active signalling, Eph receptors control a wide range of responses, including rearrangements of the actin cytoskeleton, cell attachment, repulsion, migration, proliferation and survival, in a variety of normal and malignant cell types [30, 31]. In agreement, Eph receptors are actively involved in multiple biological processes, such as embryo development [32], angiogenesis [33], bone homeostasis [34], regulation of T-cell functionality [35-37], insulin production [38] and synaptic plasticity $[31,39]$. Eph receptors also play an important role in human malignancies, including breast, colorectal, prostate, brain, skin, lung, hepatocellular, and gastric cancers [40]. As both the EphA and EphB subclasses of Eph receptors contain an intrinsically kinase-dead member, EphA10 and EphB6, respectively $[16,17,27]$, it is likely that these kinase-inactive players may have an important role in Eph receptor signalling network. While, little is known about the mechanism or impact of EphA10 signalling, the EphB6 receptor is actively involved in a number of biological responses in normal physiological conditions [41-43] and in human malignancies [19, 44-48]. Being kinase-dead, EphB6 relies on ligand-triggered tyrosine phosphorylation provided by kinase-active family members, including EphB1 and EphB4, for signal transduction $[45,49]$. This raises interesting questions about how stimulationdependent EphB6 receptor downregulation is organized and whether EphB6 follows the same route of elimination as its kinase-active partner, EphB4 [45].

In this work, we dissect the mechanisms responsible for the ligand-induced downregulation of the kinase-dead EphB6 receptor, comparing EphB6 removal with the downregulation of the EphB4 receptor, which also has not been previously assessed. According to our observations, both receptors follow the same route in their downregulation, their degradation is preceded by internalisation through clathrin-coated pits and once internalised, both are targeted in a Rab5-dependent manner towards their degradation in the lysosomal compartment. In agreement with these observations, EphB6 co-expression does not alter the rate at which EphB4 is eliminated. Most notably, our work reveals that EphB6 interacts with the Hsp90 chaperone and this interaction appears to ensure EphB6 stability, as treatment with an Hsp90 inhibitor, geldanamycin (GA), reduces EphB6 presence, with the rate of EphB6 removal closely resembling ligand-induced downregulation. Moreover, stimulation of the EphB6 receptor with its ligand, ephrin-B2 results in a rapid disruption of EphB6-Hsp90 interaction at the cell membrane that precedes EphB6 removal. Both ligand-induced and GA-triggered EphB6 degradation responses are likely to be mediated by the same molecular mechanism, as GA treatment does not provide a consistent significant enhancement to stimulation-initiated EphB6 elimination. These observations support an intriguing model, where the process of EphB6 downregulation is initiated by EphB6-Hsp90 dissociation. 
Overall, our data provide the first description of the routes of the stimulation-dependent downregulation of the kinase-deficient EphB6 receptor and its kinase-active partner, EphB4, and highlight a novel mechanism for RTK removal, which is associated with the ligand-induced disruption of a receptor-Hsp90 complex. This clarifies one of the pathways used by kinase-dead RTKs in their downregulation and may also help in understanding EphB6 action in normal physiological responses and in malignancy.

\section{Materials and Methods}

\subsection{Antibodies}

Antibodies for Myc, Erk2, $\beta$-Tubulin, EphB4, Clathrin heavy-chain, EphB4, and Eps15 were from Santa Cruz Biotechnology, goat anti-human Fc (anti-hFc) was from Pierce Biotechnology, anti-EphB6 were from Santa Cruz, R\&D Systems, and Sigma-Aldrich, anti-Hsp90 was from StressGen, and Goat F(ab')2 Anti-Human IgG (Fc) FITC was from Beckman Coulter. Ephrin-B2-Fc and fluorescein labelled anti-sheep IgG were purchased from R\&D Systems. Secondary antibodies linked to IR-dyes for Western blotting (anti-goat, anti-rabbit, anti-rat and anti-mouse) were purchased from Mandel Scientific. Anti-rat Alexafluor 594 was purchased from Cell Signalling.

\subsection{Expression constructs and shRNA}

The wild-type EphB6 receptor and EGFP-tagged EphB6 constructs were kindly provided by Dr. C.M. Roifman (Sick Children's Hospital, Toronto, ON). EphB4 and EphB4-EGFP constructs were purchased from OriGene Technologies, Inc. Myc-tagged EphB6 and an EphB6 mutant, lacking the cytoplasmic domain ( $\Delta$ EphB6) and a tyrosine to phenylalanine substitution mutant of EphB6 (EphB6 Y->F) were described previously [43, 45, 49]. Clathrin heavy chain $(\mathrm{CHC})$ shRNA lentiviral particles and control non-silencing shRNA were purchased from Santa Cruz. RFP-tagged Rab5 was provided by Dr. Anderson from the University of Saskatchewan. An Eps15 mutant, DIII, was provided by Dr. Benmerah from the Institut Imagine, Paris, France.

\subsection{Cell culture and generation of stable cell lines}

Stable cell lines of HEK-293 cells [American Type Culture Collection (ATCC)], expressing either Myc-tagged EphB4 (HEK-B4-M), EphB6 (HEK-B6), $\Delta$ EphB6 (HEK- $\Delta$ EphB6), EphB6(Y->F) (HEK-EphB6(Y->F)), EGFP-tagged EphB4 (HEK-B4-EGFP), or Myc-tagged EphB6 (HEK-B6-M) were generated by electroporation using $20 \mu \mathrm{g}$ of DNA (70 ms, 140 V, ECM 830 electroporator; Harvard Apparatus Inc.). Cells were allowed to rest overnight and were then subjected to $\mathrm{G} 418(1 \mathrm{mg} / \mathrm{ml})$ (Calbiochem) selection for 30 days. Cells were lysed and screened for Eph receptor expression by Western blotting. 
All HEK-293 based cell lines were cultured in Dulbecco's modified Eagle's medium (DMEM, HyClone), 10\% fetal bovine serum (FBS, Gibco), and $1 \mathrm{mM}$ sodium pyruvate (SP, HyClone). MDA-MB-231 (ATCC) were cultured as HEK293 with the addition of 1\% Pen Strep (Gibco). Hcc-70 (ATCC) were cultured in Roswell Park Memorial Institute (RPMI)-1640 (HyClone) medium with 10\% FBS and 0.5\% Pen Strep.

Stable cell lines with clathrin heavy chain $(\mathrm{CHC})$ knock-down were generated based on the HEK-B6 or HEK-B4M cell lines, using CHC shRNA lentiviral particles (Santa Cruz) according to the manufacturer's instructions.

\subsection{Cell stimulation}

In all experiments involving stimulation, cells were treated with $1 \mu \mathrm{g} / \mathrm{ml}$ soluble ephrin-B2-Fc precomplexed with $1.5 \mu \mathrm{g} / \mathrm{ml}$ anti-human-Fc in serum free media. Precomplexed human IgG (Sigma) was used as a specificity control for the Fc portion of the ephrin-B2-Fc (eB2) fusion protein. In some experiments, cells were preincubated at $37^{\circ} \mathrm{C}$ with 80 $\mu \mathrm{M}$ dynasore (Santa Cruz) for $1 \mathrm{~h}$ [50], $100 \mathrm{nM}$ chloroquine for $2 \mathrm{~h}$ [51], or $25 \mathrm{mM} \mathrm{NH}_{4} \mathrm{Cl}$ for $1 \mathrm{~h}$ [52], as indicated in figure legends. Inhibitor presence was maintained throughout treatment with ephrin-B2. Geldanamycin $(10 \mu \mathrm{M}, \mathrm{Santa}$ Cruz) was used with no prior incubation [53]. Matching solvents were used as controls.

\subsection{Flow Cytometry}

To confirm cell surface expression of EphB6 mutants, cells were collected with 2 mM EDTA, washed in serum free media, and incubated with anti-EphB6 or matching lgG control (R\&D Systems) for 40 min on ice. Labelled cells were washed twice with serum free media, and incubated with FITC-conjugated secondary antibody for 30 min on ice in the dark, washed twice with serum free media, and suspended in PBS for analysis.

For the ligand internalisation assay cells were stimulated for $30 \mathrm{~min}$ with $1 \mu \mathrm{g} / \mathrm{ml}$ eB2, washed with acidic PBS (0.2 M Acetic acid, pH 3.0) for 5 min 3 times, collected with 2 mM EDTA, and fixed with $1 \%$ formaldehyde in PBS, or fixed and permeabilised with 0.1\% Triton-X-100 (Sigma). Cells were stained with anti-human IgG (Fc)-FITC.

In all experiments, staining was monitored by flow-cytometry using a Coulter Epics XL or a MACSQuant VYB ( Miltenyi Biotec) Flow Cytometer. Results were analyzed with the FlowJo software.

\subsection{Cell Lysis, Immunoprecipitation and Western blotting}

Following stimulation cells were washed once in serum free media and once with PBS to remove excess ligand and ions. Cells were detached from the surface of the plate in the lysis buffer (0.1 M EDTA, 0.3 M Tris, $0.1 \mathrm{M} \mathrm{NaCl}, 6$ mM PMSF and $3 \mathrm{mM}$ sodium ortho-vanadate). For immunoprecipitation, $20 \mu \mathrm{l}$ of Protein G Sepharose beads (GE 
Healthcare) and 2- $3 \mu \mathrm{g}$ of the required antibody were added, samples were rotated at $4{ }^{\circ} \mathrm{C}$ overnight and beads were washed three times in lysis buffer. Samples were resolved by SDS-PAGE, and transferred to a nitrocellulose membrane (Amersham) for Western blotting. Images were acquired using the LI-COR Odyssey imaging system. Densitometry analysis was performed using Carestream software (Carestream Health).

\subsection{Confocal Microscopy}

Cells were plated on glass bottom culture dishes (MatTek), cultured for $24 \mathrm{~h}$, transfected with EphB6-EGFP or EphB4-EGFP cDNAs and cultured for an additional $72 \mathrm{~h}$. To examine lysosomal colocalisation, transfected cells were stained for 30 min with 60 nM LysoTracker Red DND-99 (Invitrogen) in serum-free DMEM prior to ephrin-B2 stimulation, and imaged in phenol-red free DMEM (Fisher) with 25 mM HEPES (Sigma). Hsp90 association was monitored by plating HEK-293 on glass coverslips (Fisher) pre-coated with poly-L-lysine (Trevigen), transfection with EphB6-EGFP or EphB4-EGFP construct, and stimulation $72 \mathrm{~h}$ post transfection. Cells were fixed in $4 \%$ formaldehyde/PBS for 20 min, permeabilised and blocked for $1 \mathrm{~h}$ in blocking buffer (PBS containing $5 \%$ normal horse serum (Sigma), $1 \%$ bovine serum albumin (Sigma), and $0.1 \%$ saponin (Sigma), and incubated with an antibody of interest in blocking buffer for $48-72 \mathrm{~h}$ at $4^{\circ} \mathrm{C}$. Incubation for $1 \mathrm{~h}$ with matching Alexafluor-conjugated antibodies was used for detection. ProLong Gold antifade reagent with DAPI (Invitrogen) was used as a mounting medium and provided nuclear staining. Cells were visualized using an Olympus FV1000 confocal microscope. Fixed cells were imaged using a $60 \mathrm{X}$ oil-immersion lens, whereas live cells were imaged at 40X. Live cell experiments took place in a heated imaging chamber maintained at $37^{\circ} \mathrm{C}$, with images collected prior to, and every 1 or 2 min for 20 min following the addition of ephrin-B2. All images have been subjected to deconvolution using Auto-Deblur (AutoQuant X3, Media Cybernetics). Images were processed using the Image J software (McMaster Biophotonics) and Adobe Photoshop CS6 (Adobe Systems Inc.). 3D-reconstruction was performed using the IMARIS 7.4.2 software (Bitplane). Pearson's correlation coefficients were determined using FIJI software [54].

\section{Results}

\subsection{The EphB6 receptor is actively downregulated in response to ligand stimulation}

To assess the ligand-induced downregulation of the kinase-deficient EphB6 receptor, we compared it with the downregulation of its kinase-active signalling partner, EphB4 [45]. To do this, we generated cell lines with stable expression of EphB6 (HEK-B6) or EphB4 (HEK-B4-M) by transfecting human embryonic kidney cells, HEK-293, as these cells are commonly used as a model for this type of investigation [55-59]. A Myc-tagged version of EphB4 was used in these experiments to overcome a relatively low sensitivity of available anti-EphB4 antibodies (Fig. 1 A\&B). 
Cells were stimulated for up to 3 hours with a common ligand of the EphB6 and EphB4 receptors, ephrin-B2, and as an ephrin-B2-Fc fusion protein was used for the stimulation, human IgG (hlgG) was applied as a specificity control for the human-Fc portion of this chimera. Following previously reported models related to other Eph receptors, all stimulations were performed at $1 \mu \mathrm{g} / \mathrm{ml}$ of ephrin-B2 [60, 61]. Receptor downregulation was monitored by Western blotting. These experiments showed that kinase-dead EphB6 and kinase-active EphB4 are efficiently downregulated, with both receptors being degraded following their activation (Fig. 1 C\&D). EphB6 downregulation was also observed in MDA-MB-231 breast cancer cells with restored EphB6 expression, MDA-B6-M, which express Myc-tagged EphB6 (described in our previous work [45]), and in a breast cancer cell line, HCC-70, that expresses this receptor endogenously (Fig. 1 E\&F). This indicates that our initial observations were not restricted to HEK-293, and are relevant to the mechanism acting in other cell types, including human breast cancer cells.

One of the means by which the ErbB2 receptor imparts its biological effects is through a negative impact on the downregulation of its signalling partners [8-11]. To determine if EphB6 also relies on this mode of action, we examined if EphB6 modulates EphB4 downregulation. EphB6 was transiently co-expressed in HEK-B4-M cells and ephrin-B2-induced EphB4 downregulation was monitored (Fig. 1 G). However, no consistent inhibition of EphB4 removal was observed, suggesting that EphB6 does not act by reducing the efficiency of downregulation of its signalling partners. Interestingly, we consistently could not observe downregulation of the EphB6 receptor in these experiments, most likely due to the extremely high level of continuous EphB6 production in the transient expression model.

Overall, these data demonstrate that the kinase-dead EphB6 receptor is efficiently downregulated in response to ligand stimulation in multiple cell types, and indicate that it is unlikely to function by suppressing downregulation of its kinase-active relatives.

\subsection{EphB6 receptor downregulation depends on the functional properties of its cytoplasmic domain}

As EphB4 acts as EphB6 partner and assures initiation of ligand-induced cytoplasmic signaling by this kinasedead receptor [45], we transiently transfected HEK-B6 cells with EphB4-encoding cDNA to examine if EphB4 presence would increase the rate of EphB6 downregulation. Surprisingly, no enhancement in ligand-initiated EphB6 elimination was observed in HEK-B6 cells co-expressing the EphB4 receptor (Fig. 2 A).

This observation prompted us to examine the necessity of EphB6 interactions with cytoplasmic signaling molecules for its downregulation. To exclude the possibility that ligand-induced complexing of the EphB6 receptor on the cell membrane could be sufficient to trigger its removal, we took advantage of a previously described cytoplasmic domain deletion mutant of EphB6, $\mathrm{EphB6}$ [45], that completely lacks the cytoplasmic portion. Although our flow 
cytometry analysis revealed that $\Delta \mathrm{EphB} 6$ is successfully delivered to the cell membrane (Fig. $2 \mathrm{~B}$ ), this mutation completely abolished EphB6 downregulation (Fig. 2 C), indicating that interactions with cytoplasmic molecules are likely to play a crucial role in EphB6 ligand-induced elimination. This observation is conceptually interesting, as a cytoplasmic domain deletion mutant of the kinase-dead ErbB3 receptor has been shown to undergo ligand-induced internalisation [24]. To further clarify the importance of the fully-functional cytoplasmic domain for EphB6 downregulation, a previously generated EphB6 mutant with all tyrosine residues in its cytoplasmic domain substituted for phenylalanines (EphB6 Y->F) [45], was expressed in HEK-293 cells (Fig. 2 B). Interestingly, no downregulation of this mutant was observed (Fig. 2 D), confirming that intact cytoplasmic signaling motifs are required for EphB6 downregulation.

\subsection{EphB6 and EphB4 downregulation is preceded by their internalisation through clathrin-coated pits}

To further follow the route leading to EphB6 and EphB4 downregulation, we examined if they are internalised prior to their degradation. HEK-B6 or HEK-B4-M cells were treated with ephrin-B2-Fc, washed with acidic PBS, as previously described [62], to remove receptor-bound ligand from the cell surface, fixed with formaldehyde, or fixed and permeabilised with Triton-X-100. Cells were stained with anti-Fc-FITC and analyzed by flow cytometry. A stronger staining was consistently observed in permeabilised cells, indicating that receptor-ligand complexes were efficiently internalised (Fig. 3 A). No internalisation-related staining could be observed in control mock-transfected cells (HEK-pc3), confirming that the observed response was specific to EphB6 and EphB4 receptors.

The final step of internalisation culminates in pinching off the endocytic vesicle from the cell membrane, and this step is frequently controlled by a large GTPase, dynamin [63]. Indeed, degradation of both EphB6 and EphB4 was reduced when they were stimulated with ephrin-B2 in the presence of the dynamin inhibitor, dynasore [64] (Fig. 3 $B \& C)$, further confirming the importance of internalisation for the downregulation of these receptors. In some experiments, increased EphB6 receptor levels could be observed in the presence of dynasore, indicating that dynamin is also involved in mediating basal, ligand-independent EphB6 degradation.

In response to ligand stimulation, RTKs are often internalised through clathrin-coated pits (CCPs), structures formed on the inner surface of the cell membrane by a complex of proteins, including clathrin [65]. However some Eph receptors, including EphB1 and EphA2, have been shown to interact with caveolin-1, a protein associated with another endocytic membrane structure, caveolae $[61,66]$. To examine if EphB6 and EphB4 preferentially use the CCP-mediated gateway, we took advantage of a previously described dominant-negative mutant of the Eps 15 adaptor protein, DIII, [67], as Eps15 is actively involved in CCP-dependent endocytosis [67-69]. This mutant lacks all Eps homology $(\mathrm{EH})$ domains that target it to CCPs and represents only the DIII domain responsible for binding to the 
clathrin adaptor protein, AP-2. DIII prevents wild-type Eps15 from interacting with AP-2, which is required for receptor internalisation through CCPs, and has been shown to block CCP formation [67, 69]. In agreement, the stimulation-initiated downregulation was strongly reduced for both EphB4 and EphB6, when this mutant was expressed (Fig. 4 A-D), strongly implicating CCP in the internalisation and subsequent downregulation of these receptors. In these experiments, the extent of DIII effects matched well the efficiency of its action reported by other groups [70]. To further verify the role of CCP-mediated internalisation in EphB4 and EphB6 downregulation, we partially silenced $\mathrm{CHC}$ expression in HEK-B6 and HEK-B4-M cells with $\mathrm{CHC}$-targeting shRNA and as expected, this decrease in $\mathrm{CHC}$ level greatly reduced ligand-triggered receptor removal (Fig. $4 \mathrm{E}-\mathrm{H}$ ).

Overall, these data imply that both EphB4 and EphB6 rely on CCP-dependent internalisation for their downregulation.

\subsection{Both EphB6 and EphB4 are degraded in the lysosomal compartment}

Following activation and internalisation, a significant portion of receptor molecules are destined for degradation, which is often performed in the lysosomal compartment [71]. We monitored EphB6 and EphB4 ligand-induced relocalisation into these organelles in cells stained with the lysosomal-specific dye, LysoTracker Red [72] (Fig. 5 A\&B, Fig. S 1\&2). Interestingly, a strong increase in the localisation of EphB6 and EphB4 in lysosomes was observed following ephrin-B2 treatment, suggesting that ligand-induced receptor degradation was likely performed in the lysosomal compartment. To assess this possibility, HEK-B6 and HEK-B4-M were treated with the lysosomal inhibitors, chloroquine and ammonium chloride [73, 74]. The ligand-induced degradation of both EphB6 and EphB4 was strongly suppressed by these inhibitors, thereby confirming a central role for the lysosomal compartment in their downregulation (Fig. 5 C-F).

Trafficking of internalised receptors from the plasma membrane to lysosomes is in part, mediated by early endosomes that are actively regulated by the Rab5 GTPase [75]. In agreement, EphB6 and EphB4 downregulation was greatly impaired in the presence of a Rab5 dominant-negative mutant, Rab5 S34N [76] (Fig. 6 A\&B), suggesting that the endosomal route is involved in targeting them for degradation.

In sum, our observations show that the kinase-deficient EphB6, and kinase-active EphB4 receptors are efficiently downregulated in response to ligand stimulation. Both receptors follow the same pathway in their ligandinduced internalisation, trafficking and degradation, relying on CCPs for internalisation, dynamin for membrane scission and on Rab5 for cytoplasmic trafficking, whereas their degradation is carried out in the lysosomal compartment. 


\subsection{EphB6 stability is supported by the stimulation-sensitive interaction with Hsp90}

Hsp90 is a well-documented chaperone responsible for the proper folding, stability, and turnover of a wide range of proteins [77]. In addition to its role in protein stability, Hsp90 has also been implicated in assisting in the maintenance of proteins at the cell surface and in ensuring the availability of receptors for ligand-binding [78-81]. Our co-immunoprecipitation experiments showed that EphB6 also interacts with Hsp90, and that this interaction was rapidly disrupted by treatment with ephrin-B2. The effect could be readily observed after five minutes of stimulation

(Fig. 7 A). Similar experiments were performed with the EphB4 receptor, however, we were unable to consistently detect the EphB4-Hsp90 interaction. To determine the localisation of the EphB6-Hsp90 complexes affected by ephrin-B2 stimulation, EphB6-EGFP-expressing HEK-293 cells were stimulated with ephrin-B2 for 20 minutes and stained with anti-Hsp90. Interestingly, a strong colocalisation of EphB6 with Hsp90 was observed at the cell membrane in unstimulated cells and this co-localisation was very significantly reduced upon ephrin-B2 treatment. While some minimal presence of cytoplasmic complexes was also observed, there was no major change in cytoplasmic EphB6-Hsp90 colocalisation in response to ephrin-B2 treatment (Fig. 7 B, Fig. S 3, and Movies S1 \& 2). These novel observations suggest that Hsp90 and EphB6 interact mostly at the cell membrane and to a lesser degree inside the cell, and that the interaction at the membrane is terminated following activation of EphB6 by its ligand.

To examine if the absence of Hsp90 support was sufficient to initiate EphB6 degradation, we treated HEK-B6 cells with the Hsp90 inhibitor, geldanamycin (GA) [82]. This treatment triggered EphB6 downregulation at a rate that was similar to the rate of its ephrin-B2-initiated removal (Fig. $7 \mathrm{C}$ ). While GA application on its own resulted in strong EphB6 degradation, no consistent or statistically significant increase in the efficiency of ligand-induced receptor downregulation could be observed in response to simultaneous co-treatment with ephrin-B2 and GA (Fig. 7 D). This lack of a significant enhancing effect indicates that stimulation-induced EphB6 downregulation and GA-initiated degradation are likely to rely on an overlapping molecular mechanism.

Overall, these observations suggest an entirely new model, where the rapid disruption of the EphB6-Hsp90 complex in response to ligand treatment may represent a key event in the initiation of EphB6 stimulation-induced downregulation.

\section{Discussion}

Stimulation-induced receptor downregulation through internalisation and subsequent targeted degradation play an important role in controlling cellular responses by both enhancing and suppressing cytoplasmic signalling [83]. 
While these processes are well described for the EGFR receptor [84], much less is understood about downregulation of Eph receptors. Available data are not systematic and imply that different Ephs may use very distinct mechanisms. For example, ligand-induced downregulation of the EphA2 receptor relies on its degradation in the lysosomal compartment [85], while in contrast, stimulation-initiated EphA3 elimination is mediated by proteasomal complexes [86]. Both EphA8 [87] and EphB1 [88] are endocytosed through CCPs following ligand stimulation, and internalised EphB1 is degraded in the lysosomal compartment inside the cell [60]. Unlike these examples, EphB2 proteolysis in response to ligand stimulation is performed by the $\gamma$-secretase complex and is triggered by the initial ligand-induced cleavage of EphB2 by metalloproteases at the cell membrane [51]. In this situation, it is not a surprise that despite the recent accumulation of data that highlight an important role for one of Eph receptors, EphB6, in both normal physiology and in malignancy [19, 41-48], the molecular mechanism of its downregulation has never been investigated. Such an investigation appears especially attractive in light of an unusual nature of this protein, which is kinase-inactive, despite its association with the Eph group of RTKs [27]. Until now, downregulation of only one other kinase-deficient RTK, the ErbB3 receptor, has been dissected and yet, even this remains not well understood, as multiple reports suggest that ErbB3 is internalisation- and downregulation- deficient, while some recent observations show that ErbB3 undergoes ubiquitination and is efficiently downregulated in response to ligand stimulation [21-26].

Our work presented here, attempts to systematically analyse the mechanism of ligand-induced downregulation of the kinase-dead EphB6 receptor, while comparing it with the downregulation of its kinase-active relative and signaling partner, EphB4 [45], which also has not been previously assessed. It shows that similarly to the EphB4 receptor, EphB6 is actively downregulated in response to ligand stimulation and does not suppress EphB4 downregulation. In agreement, following treatment with their common ligand, ephrin-B2, both receptors are internalised through clathrin-coated pits and both are eventually, targeted towards their degradation in the lysosomal compartment in a Rab5-dependent manner. Efficient receptor internalisation requires separation of the endocytic vesicles from the cell membrane into the cytoplasm and the dynamin GTPase is usually in charge of this process [63]. Matching our other observations, ligand-induced downregulation of both EphB6 and EphB4 proved to require dynamin activitiy.

Although RTKs are frequently targeted for degradation by stimulation-triggered ubiquitination [89], we could not detect an increase in EphB6 or EphB4 ubiquitination following ephrin-B2 treatment even in ubiquitin-overexpressing cells (not shown). This suggests that unlike some other RTKs, including ErbB3 [25] and EphB1 [60], EphB6 and EphB4 may be targeted for lysosomal degradation by a ubiquitin-independent mechanism. Recently, a G proteincoupled receptor, PAR1, has been reported to act in a similar manner, as it is targeted for lysosomal degradation not by ubiquitination, but rather through its association with a multivesicular body protein, ALIX [90]. It is possible that 
ALIX is also involved in EphB6 and EphB4 targeting, and this possibility is under an active investigation in our laboratory.

The EphB6 receptor appears to involve one more interesting trait in its downregulation. In the absence of stimulation, EphB6 consistently interacts with the Hsp90 chaperone that is known to bind to and stabilize few other RTKs, including EGFR and ErbB2 [81, 91]. According to our confocal microscopy data, Hsp90 stabilizes the EphB6 receptor predominantly at the cell surface, as the EphB6-Hsp90 interaction is compartmentalized mostly in this area. Intriguingly, the membrane-associated EphB6-Hsp90 complex is rapidly disrupted following ligand application and this response precedes EphB6 degradation, implying that EphB6 downregulation could be triggered by modifications caused by ligand-induced Hsp90 dissociation. This possibility is strongly supported by our data, showing that inhibition of Hsp90 activity results in EphB6 elimination at a rate that closely resembles the rate of its ephrin-B2triggered downregulation. Moreover, Hsp90 inhibition does not produce any consistent significant increase in ligandinduced EphB6 removal, strongly suggesting that in both cases, receptor downregulation is executed by the same molecular mechanism that is most likely initiated by the lack of Hsp90 activity. This is in contrast to EGFR behaviour, which has been reported to be downregulated much more efficiently when simultaneously treated with its ligand, EGF, and GA in comparison to each individual treatment alone [92].

This mode of action has not been reported previously in relation to ligand-induced receptor degradation, and it remains to be seen if it represents a frequent approach to downregulation of Eph receptors or RTKs in general, or if it is EphB6-specific. Interestingly, the Eph group contains one more kinase-deficient member, the EphA10 receptor [16]. Its functional properties are still enigmatic and it would be curious to see if its downregulation is also governed by Hsp90.

At this stage, Hsp90 inhibitors are being tested in clinical trials for treating ErbB2-overexpressing breast cancer [93]. As previous observations indicate that the EphB6 receptor acts to suppress breast cancer aggressiveness [44, 45], our current data, showing that Hsp90 inhibition reduces EphB6 presence, suggest that this approach should be applied with caution to EphB6-expressing breast cancer tumours. To clarify this, potential unfavorable aspects of Hsp90 inhibition are currently being analyzed in our animal model of EphB6-positive breast cancer.

Overall, our work provides the first description of the route of ligand-induced downregulation of an intrinsically kinase-deficient member of the Eph group of RTKs, EphB6, and shows that EphB6 is removed in a manner that is very similar to the mode of downregulation of its kinase-active relative, the EphB4 receptor. Perhaps more importantly, our observations present the first example of Eph receptor interaction with the Hsp90 chaperone and reveal that stimulation-dependent EphB6 degradation is preceded by the disruption of its association with Hsp90, which likely acts as downregulation trigger (Figure 8). To our knowledge, this model has not been previously 
discussed and this mechanism may potentially represent a frequently used stage in ligand-induced RTK downregulation, shared by multiple family members on their way to lysosomal degradation.

Acknowledgments: We gratefully acknowledge Dr. Luke Truitt (Translational Cancer Research Unit, University of Saskatchewan) for his guidance and assistance in technical matters. This work was funded by the Canadian Institutes of Health Research grants (COP-107969 and RSN-132192) and SHRF grant (2891). O.A. was funded by a Graduate Research Award from the University of Saskatchewan.

We do not have any conflict of interests to declare. 


\section{References}

[1] Casaletto JB, McClatchey Al, Nat Rev Cancer 12 (2012) 6 387-400.

[2] Haugh JM, Huang AC, Wiley HS, Wells A, Lauffenburger DA, J Biol Chem 274 (1999) 48 34350-34360.

[3] Abella JV, Park M, Am J Physiol Endocrinol Metab 296 (2009) 5 E973-984.

[4] Mosesson Y, Mills GB, Yarden Y, Nat Rev Cancer 8 (2008) 11 835-850.

[5] Abella JV, Peschard P, Naujokas MA, Lin T, Saucier C, Urbe S, Park M, Mol Cell Biol 25 (2005) 21 9632-9645.

[6] Ridge SA, Worwood M, Oscier D, Jacobs A, Padua RA, Proc Natl Acad Sci U S A 87 (1990) 4 1377-1380.

[7] Herbst R, Munemitsu S, Ullrich A, Oncogene 10 (1995) 2 369-379.

[8] Wang Z, Zhang L, Yeung TK, Chen X, Mol Biol Cell 10 (1999) 5 1621-1636.

[9] Haslekas C, Breen K, Pedersen KW, Johannessen LE, Stang E, Madshus IH, Mol Biol Cell 16 (2005) 12 58325842.

[10] Lenferink AE, Pinkas-Kramarski R, van de Poll ML, van Vugt MJ, Klapper LN, Tzahar E, Waterman H, Sela M, van Zoelen EJ, Yarden Y, EMBO J 17 (1998) 12 3385-3397.

[11] Worthylake R, Opresko LK, Wiley HS, J Biol Chem 274 (1999) 13 8865-8874.

[12] Parachoniak CA, Park M, Trends Cell Biol 22 (2012) 5 231-240.

[13] Baselga J, Swain SM, Nat Rev Cancer 9 (2009) 7 463-475.

[14] Katso RM, Russell RB, Ganesan TS, Mol Cell Biol 19 (1999) 9 6427-6440.

[15] Mossie K, Jallal B, Alves F, Sures I, Plowman GD, Ullrich A, Oncogene 11 (1995) 10 2179-2184.

[16] Aasheim HC, Patzke S, Hjorthaug HS, Finne EF, Biochim Biophys Acta 1723 (2005) 1-3 1-7.

[17] Gurniak CB, Berg LJ, Oncogene 13 (1996) 4 777-786.

[18] Sierke SL, Cheng K, Kim HH, Koland JG, Biochem J 322 ( Pt 3) (1997) 757-763.

[19] Truitt L, Freywald A, Biochem Cell Biol 89 (2011) 2 115-129.

[20] Clark CE, Nourse CC, Cooper HM, Neurosignals 20 (2012) 3 202-220.

[21] Baulida J, Kraus MH, Alimandi M, Di Fiore PP, Carpenter G, J Biol Chem 271 (1996) 9 5251-5257.

[22] Chen X, Levkowitz G, Tzahar E, Karunagaran D, Lavi S, Ben-Baruch N, Leitner O, Ratzkin BJ, Bacus SS, Yarden Y, J Biol Chem 271 (1996) 13 7620-7629.

[23] Daly JM, Jannot CB, Beerli RR, Graus-Porta D, Maurer FG, Hynes NE, Cancer Res 57 (1997) $173804-3811$.

[24] Waterman H, Sabanai I, Geiger B, Yarden Y, J Biol Chem 273 (1998) 22 13819-13827.

[25] Cao Z, Wu X, Yen L, Sweeney C, Carraway KL, 3rd, Mol Cell Biol 27 (2007) 6 2180-2188.

[26] Sak MM, Szymanska M, Bertelsen V, Hasmann M, Madshus IH, Stang E, Carcinogenesis 34 (2013) 92031 2038.

[27] Matsuoka H, Iwata N, Ito M, Shimoyama M, Nagata A, Chihara K, Takai S, Matsui T, Biochem Biophys Res Commun 235 (1997) 3 487-492.

[28] Hirai H, Maru Y, Hagiwara K, Nishida J, Takaku F, Science 238 (1987) 4834 1717-1720.

[29] Janes PW, Nievergall E, Lackmann M, Semin Cell Dev Biol 23 (2012) 143-50.

[30] Pasquale EB, Nat Rev Mol Cell Biol 6 (2005) 6 462-475.

[31] Pasquale EB, Nat Rev Cancer 10 (2010) 3 165-180.

[32] Klein R, Development 139 (2012) 22 4105-4109.

[33] Salvucci O, Tosato G, Adv Cancer Res 114 (2012) 21-57.

[34] Matsuo K, Otaki N, Cell Adh Migr 6 (2012) 2 148-156.

[35] Wu J, Luo H, Curr Opin Hematol 12 (2005) 4 292-297.

[36] Alfaro D, Garcia-Ceca JJ, Cejalvo T, Jimenez E, Jenkinson EJ, Anderson G, Munoz JJ, Zapata A, Eur J Immunol 37 (2007) 9 2596-2605.

[37] Alfaro D, Munoz JJ, Garcia-Ceca J, Cejalvo T, Jimenez E, Zapata AG, Immunol Cell Biol 89 (2011) 8 844-852.

[38] Konstantinova I, Nikolova G, Ohara-Imaizumi M, Meda P, Kucera T, Zarbalis K, Wurst W, Nagamatsu S,

Lammert E, Cell 129 (2007) 2 359-370.

[39] Klein R, Nat Neurosci 12 (2009) 1 15-20.

[40] Xi HQ, Wu XS, Wei B, Chen L, J Cell Mol Med 16 (2012) 12 2894-2909.

[41] Luo H, Wu Z, Tremblay J, Thorin E, Peng J, Lavoie JL, Hu B, Stoyanova E, Cloutier G, Qi S, Wu T, Cameron M, Wu J, J Biol Chem 287 (2012) 9 6819-6829.

[42] Luo H, Yu G, Tremblay J, Wu J, J Clin Invest 114 (2004) 12 1762-1773.

[43] Freywald A, Sharfe N, Rashotte C, Grunberger T, Roifman CM, J Biol Chem 278 (2003) 12 10150-10156.

[44] Fox BP, Kandpal RP, Oncogene 28 (2009) 14 1706-1713.

[45] Truitt L, Freywald T, DeCoteau J, Sharfe N, Freywald A, Cancer Res 70 (2010) 3 1141-1153.

[46] Maddigan A, Truitt L, Arsenault R, Freywald T, Allonby O, Dean J, Narendran A, Xiang J, Weng A, Napper S, Freywald A, J Immunol 187 (2011) 11 5983-5994.

[47] Yu J, Bulk E, Ji P, Hascher A, Tang M, Metzger R, Marra A, Serve H, Berdel WE, Wiewroth R, Koschmieder S, Muller-Tidow C, Clin Cancer Res 16 (2010) 8 2275-2283.

[48] Tang XX, Zhao H, Robinson ME, Cohen B, Cnaan A, London W, Cohn SL, Cheung NK, Brodeur GM, Evans AE, Ikegaki N, Proc Natl Acad Sci U S A 97 (2000) 20 10936-10941.

[49] Freywald A, Sharfe N, Roifman CM, J Biol Chem 277 (2002) 6 3823-3828. 
[50] Garcia Lopez MA, Aguado Martinez A, Lamaze C, Martinez AC, Fischer T, Cell Signal 21 (2009) 12 1748-1757. [51] Litterst C, Georgakopoulos A, Shioi J, Ghersi E, Wisniewski T, Wang R, Ludwig A, Robakis NK, J Biol Chem 282 (2007) 22 16155-16163.

[52] Jia L, Yu G, Zhang Y, Wang MM, Int J Biochem Cell Biol 41 (2009) 12 2594-2598.

[53] Whitesell L, Mimnaugh EG, De Costa B, Myers CE, Neckers LM, Proc Natl Acad Sci U S A 91 (1994) $188324-$ 8328.

[54] Nat Methods 9 (2012) 7627.

[55] Stautz D, Leyme A, Grandal MV, Albrechtsen R, van Deurs B, Wewer U, Kveiborg M, Traffic 13 (2012) 11 15321546.

[56] Thompson D, Whistler JL, Traffic 12 (2011) 5 644-656.

[57] Yancoski J, Sadat MA, Aksentijevich N, Bernasconi A, Holland SM, Rosenzweig SD, J Leukoc Biol 92 (2012) 2 301-308.

[58] Gironacci MM, Adamo HP, Corradi G, Santos RA, Ortiz P, Carretero OA, Hypertension 58 (2011) $2176-181$.

[59] Cui W, Simaan M, Laporte S, Lodge R, Cianflone K, Mol Immunol 46 (2009) 15 3086-3098.

[60] Fasen K, Cerretti DP, Huynh-Do U, Traffic 9 (2008) 2 251-266.

[61] Vihanto MM, Vindis C, Djonov V, Cerretti DP, Huynh-Do U, J Cell Sci 119 (2006) Pt 11 2299-2309.

[62] Olwill SA, Joffroy C, Gille H, Vigna E, Matschiner G, Allersdorfer A, Lunde BM, Jaworski J, Burrows JF, Chiriaco C, Christian HJ, Hulsmeyer M, Trentmann S, Jensen K, Hohlbaum AM, Audoly L, Mol Cancer Ther 12 (2013) 11 2459-2471.

[63] Ferguson SM, De Camilli P, Nat Rev Mol Cell Biol 13 (2012) 2 75-88.

[64] Thompson HM, McNiven MA, Nat Chem Biol 2 (2006) 7 355-356.

[65] Doherty GJ, McMahon HT, Annu Rev Biochem 78 (2009) 857-902.

[66] Sainz-Jaspeado M, Huertas-Martinez J, Lagares-Tena L, Martin Liberal J, Mateo-Lozano S, de Alava E, de Torres C, Mora J, Del Muro XG, Tirado OM, PLoS One 8 (2013) 8 e71449.

[67] Benmerah A, Lamaze C, Begue B, Schmid SL, Dautry-Varsat A, Cerf-Bensussan N, J Cell Biol 140 (1998) 5 1055-1062.

[68] Parachoniak CA, Park M, J Biol Chem 284 (2009) 13 8382-8394.

[69] Benmerah A, Poupon V, Cerf-Bensussan N, Dautry-Varsat A, J Biol Chem 275 (2000) 5 3288-3295.

[70] Benmerah A, Bayrou M, Cerf-Bensussan N, Dautry-Varsat A, J Cell Sci 112 ( Pt 9) (1999) 1303-1311.

[71] Clague MJ, Urbe S, Cell 143 (2010) 5 682-685.

[72] Chazotte B, Cold Spring Harb Protoc 2011 (2011) 2 pdb prot5571.

[73] Poole B, Ohkuma S, Warburton MJ, Acta Biol Med Ger 36 (1977) 11-12 1777-1788.

[74] Amenta JS, Brocher SC, J Cell Physiol 102 (1980) 2 259-266.

[75] Huotari J, Helenius A, EMBO J 30 (2011) 17 3481-3500.

[76] Volpicelli LA, Lah JJ, Levey AI, J Biol Chem 276 (2001) 50 47590-47598.

[77] Saibil H, Nat Rev Mol Cell Biol 14 (2013) 10 630-642.

[78] Sidera K, Gaitanou M, Stellas D, Matsas R, Patsavoudi E, J Biol Chem 283 (2008) 4 2031-2041.

[79] Wayne N, Mishra P, Bolon DN, Methods Mol Biol 787 (2011) 33-44.

[80] Xu W, Yuan X, Beebe K, Xiang Z, Neckers L, Mol Cell Biol 27 (2007) 1 220-228.

[81] Xu W, Mimnaugh E, Rosser MF, Nicchitta C, Marcu M, Yarden Y, Neckers L, J Biol Chem 276 (2001) $53702-$

3708.

[82] Miyata Y, Curr Pharm Des 11 (2005) 9 1131-1138.

[83] Platta HW, Stenmark H, Curr Opin Cell Biol 23 (2011) 4 393-403.

[84] Sorkin A, Goh LK, Exp Cell Res 315 (2009) 4 683-696.

[85] Boissier P, Chen J, Huynh-Do U, Traffic (2013).

[86] Sharfe N, Freywald A, Toro A, Roifman CM, J Immunol 170 (2003) 12 6024-6032.

[87] Yoo S, Shin J, Park S, Mol Cells 29 (2010) 6 603-609.

[88] Parker M, Roberts R, Enriquez M, Zhao X, Takahashi T, Pat Cerretti D, Daniel T, Chen J, Biochem Biophys Res Commun 323 (2004) 1 17-23.

[89] Piper RC, Dikic I, Lukacs GL, Cold Spring Harb Perspect Biol 6 (2014) 1.

[90] Dores MR, Paing MM, Lin H, Montagne WA, Marchese A, Trejo J, Mol Biol Cell 23 (2012) 18 3612-3623.

[91] Ahsan A, Ramanand SG, Whitehead C, Hiniker SM, Rehemtulla A, Pratt WB, Jolly S, Gouveia C, Truong K, Van Waes C, Ray D, Lawrence TS, Nyati MK, Neoplasia 14 (2012) 8 670-677.

[92] Pedersen NM, Breen K, Rodland MS, Haslekas C, Stang E, Madshus IH, Mol Cancer Res 7 (2009) 2 275-284.

[93] Garcia-Carbonero R, Carnero A, Paz-Ares L, Lancet Oncol 14 (2013) 9 e358-369. 


\section{Figure Legends}

Figure 1. EphB6 and EphB4 are downregulated in a similar manner in response to ligand stimulation.

A and B) Human embryonic kidney cells (HEK-293), were electroporated with the pcDNA3 expression vector encoding EphB6 (HEK-B6) (A), or Myc-tagged EphB4 (HEK-B4-M) (B). Cells were cultured in G418 (1 mg/ml) selection medium for 30 days and receptor expression was analyzed by Western blotting with anti-EphB6 or anti-Myc. Cells mock-transfected with the empty pcDNA3 expression vector (HEK-pc3) were used as a specificity control. HEK293 cells transiently transfected with EphB6 or Myc-tagged EphB4 cDNAs were used as a positive control (P.C.). Western blotting of different slices of the same membranes with anti-Erk2 was used as loading control. C) HEK-B6 cells were stimulated for the indicated time periods at $37^{\circ} \mathrm{C}$ with $1 \mu \mathrm{g} / \mathrm{ml}$ of ephrin-B2-Fc (eB2). EphB6 downregulation was assessed by Western blotting with anti-EphB6 and gel loading was monitored by Western blotting with anti-Erk2. The results of Western blotting were quantitated by densitometry. EphB6 quantifications were normalized on matching Erk2 loading controls and plotted as a percentage relative to the unstimulated control (\%EphB6/hlgG). D) HEK-B4-M cells were treated as in (C). EphB4 presence was monitored by Western blotting with anti-Myc and receptor downregulation was assessed and presented as in (C). E) EphB6-expressing MDA-MB-231 cells [45] were stimulated with eB2 and EphB6 downregulation was monitored and assessed as in (C). F) HCC-70 breast cancer cells were treated with eB2 and EphB6 downregulation was monitored as in (C). G) HEK-B4-M cells were transiently transfected with EphB6 or mock-transfected with the pcDNA3 expression vector and EphB4 downregulation was examined as in (C). EphB6 expression was confirmed by Western blotting with anti-EphB6. Each graph in this figure summarises the analysis of three independent experiments, bars, SD. *, P $<0.05$, Student's t test, for indicated points and corresponding controls. Statistical analysis in panel G revealed no significant difference in the rates of eB2-induced EphB4 removal between pcDNA3- or EphB6- transfected cells at any time point monitored. All Western blot panels represent one of at least three independent experiments. In all receptor downregulation experiments, unstimulated cells (-) were treated with human $\lg G(\mathrm{hlg} G)$ for time periods matching the longest eB2 stimulation, as a specificity control for the Fc portion of the eB2 fusion protein.

Figure 2. EphB6 downregulation depends on its functional cytoplasmic domain. A) HEK-B6 cells were transfected with EphB4-encoding pcDNA3 or mock-transfected as indicated and EphB6 downregulation was analyzed as in (Fig. 1 C). EphB4 expression was confirmed with anti-EphB4. B) HEK-293 cells with stable expression of an EphB6 mutant lacking the cytoplasmic domain (HEK- $\Delta$ EphB6) or a tyrosine-deficient EphB6 mutant with all cytoplasmic tyrosine residues mutated to phenylalanine (HEK-EphB6 (Y->F)) were generated as in (Fig. $1 \mathrm{~A})$. HEK- 
$\Delta$ EphB6 and HEK-EphB6 (Y->F) cells were stained with anti-EphB6 and FITC-conjugated secondary antibodies. Staining with a matching IgG control and staining of mock-transfected HEK-pc3 cells were used as specificity controls in each experiment. Cell debris were gated out and cell staining was analysed by flow cytometry. C) HEK-B6 and HEK- $\triangle E$ phB6 cells were stimulated with eB2 for the indicated time periods and receptor downregulation was monitored and assessed as in (Fig. 1 C). D) HEK-EphB6 (Y->F) downregulation was analyzed as in (Fig. 1 C). HEKB6 cells were used as a control. Each graph summarises the analysis of three independent experiments, bars, SD. *, $P<0.05$, Student's $t$ test, for indicated points and corresponding controls, as shown. Statistical analysis in panel A revealed no significant difference in the rates of eB2-induced EphB6 removal between pcDNA3- or EphB4transfected cells at any time point monitored. All Western blot and Flow cytometry panels in this figure represent one of at least three independent experiments. In all downregulation experiments, unstimulated cell were treated with hlgG as a specificity control.

Figure 3. EphB6 and EphB4 ligand-induced downregulation depends on their dynamin-mediated internalisation. A) HEK-pc3, HEK-B6 or HEK-B4-M cells were stimulated for $30 \mathrm{~min}$ with $1 \mu \mathrm{g} / \mathrm{ml}$ of eB2, washed with acidic PBS (pH 3.0) for 5 min 3 times, collected with 2 mM EDTA, and fixed with 1\% formaldehyde in PBS (red) or fixed and permeabilized with $0.1 \%$ Triton-X-100 (blue). Cells were stained with FITC-labelled anti-human Fc antibody, and the ligand-receptor complex was detected by flow cytometry. Results were analyzed with the FlowJo software. B) HEK-B6 cells were pre-treated with $80 \mu \mathrm{M}$ of a dynamin inhibitor, dynasore, or a matching volume of DMSO as a solvent control, for $1 \mathrm{~h}$ and stimulated with eB2 for the indicated time periods. EphB6 downregulation was assessed and presented as in (Fig. 1 C). C) HEK-B4-M cells were treated as in (B) and EphB4 downregulation was monitored as in (Fig. $1 \mathrm{C}$ ). All Western blot and Flow cytometry panels in this figure represent one of at least three independent experiments. Each graph summarises the analysis of at least three independent experiments, bars, SD. *, $\mathrm{P}<0.05$, Student's $\mathrm{t}$ test, for indicated points and corresponding controls, as shown.

\section{Figure 4. EphB6 and EphB4 downregulation proceeds in a clathrin-dependent manner. A) HEK-B6 cells were} transfected with a dominant-negative mutant of Eps15 (DIII) or an irrelevant cDNA as a control and stimulated for the indicated time periods with eB2. EphB6 downregulation was monitored and assessed as in (Fig. 1 C). B) DIII expression in samples from (A) was examined by Western blotting with anti-Eps15; Western blotting with anti-Erk2 was used as a loading control. C) HEK-B4-M cells were transfected and treated as in (A), and EphB4 downregulation was analyzed and presented as in (Fig. 1 C). D) DIIl expression in samples from panel (C) was assessed as in (B). E) HEK-B6 cells were transduced with shRNA targeting clathrin heavy-chain (CHC shRNA), or non-silencing shRNA (ns 
shRNA) in the presence of $5 \mu \mathrm{g} / \mathrm{ml}$ of Polybrene overnight, and placed on puromycin selection ( $2 \mu \mathrm{g} / \mathrm{ml})$ for 3 days. Selected cells were stimulated with eB2 for the indicated time periods and EphB6 downregulation was examined as in (Fig. 1 C). F) CHC expression in samples from panel (E) was monitored with anti-CHC. G) HEK-B4-M cells were transfected and treated as in (E) and EphB4 downregulation was assessed as in (Fig. $1 \mathrm{C})$. H) CHC levels for panel $\mathrm{G}$ were monitored as in $(F)$. All Western blot panels in this figure represent one of at least three independent experiments. Each graph summarises the analysis of at least three independent experiments, bars, SD. ${ }^{*}, \mathrm{P}<0.05$, Student's t test, for indicated points and corresponding controls as shown.

\section{Figure 5. In response to ligand stimulation, EphB6 and EphB4 are degraded in the lysosomal compartment.}

A) HEK-293 cells were seeded onto glass-bottomed plates, transfected with cDNA encoding an EphB6-EGFP fusion protein, and cultured for $72 \mathrm{~h}$. Cells were stained with $60 \mathrm{nM}$ LysoTracker Red DND99 for 30 min, washed twice with phenol red-free media, and stimulated at $37^{\circ} \mathrm{C}$ for the indicated time periods. Cells were visualized at $40 \mathrm{X}$ magnification with an Olympus FV 1000 confocal microscope prior to, and at each minute following the addition of eB2 $(1 \mu \mathrm{g} / \mathrm{ml})$ for a total of $20 \mathrm{~min}$. Images were deconvoluted using AutoQuant X3. Scale bar is equal to $10 \mu \mathrm{m}$. Pearson's coefficient was determined using FIJI software, and values shown represent values obtained from at least 50 cells selected from 3 independent experiments. B) HEK-293 cells expressing EphB4-EGFP (HEK-B4-EGFP) were seeded, stained, treated, and visualized as in (A). In both A and B, graphs represent quantifications of colocalisation of LysoTracker Red with EphB6 or EphB4 using Pearson's correlation coefficient. Values were obtained from at least 50 cells from 3 independent experiments for each receptor. ${ }^{* *}, \mathrm{P}<2 \times 10^{-6}$. C) HEK-B6 cells were pre-treated with $100 \mathrm{nM}$ of a lysosome inhibitor, chloroquine (CQ), for $2 \mathrm{~h}$ and stimulated with eB2 for the indicated time periods. Receptor degradation was analyzed and presented as in (Fig. 1 C). D) HEK-B4-M cells were treated as in (C), and EphB4 degradation was monitored as in (Fig. 1 C). E) HEK-B6 cells were pre-treated with 25 $\mathrm{mM}$ of $\mathrm{NH}_{4} \mathrm{Cl}$ for $1 \mathrm{~h}$ and stimulated with eB2. EphB6 degradation was monitored and presented as in (Fig. $\left.1 \mathrm{C}\right) . \mathrm{F}$ ) HEK-B4-M cells were treated as in (E) and EphB4 degradation assessed as in (Fig. $1 \mathrm{C})$. All Western blot and confocal microscopy images in this figure represent one of at least three independent experiments. Each graph summarises the analysis of at least three independent experiments, bars, SD. * $P<0.05$, Student's test, for indicated points and corresponding controls, as shown.

\section{Figure 6: Rab5 is required for trafficking of EphB6 and EphB4 for degradation. A) HEK-B6 cells were} transfected with an HA-tagged dominant-negative mutant of Rab5, Rab5 S34N, or mock-transfected with pcDNA3 as a control and stimulated for the indicated time periods with eB2. EphB6 downregulation was monitored and assessed as in (Fig. 1 C). Expression of the mutant Rab5 was confirmed by Western blotting with anti-HA. B) HEK-B4-M cells 
were transfected and treated as in (A), and EphB4 degradation was assessed as in (Fig. $1 \mathrm{C})$. All Western blot panels in this figure represent one of at least three independent experiments. Each graph summarises the analysis of at least three independent experiments, bars, SD. * $\mathrm{P}<0.05$, Student's $t$ test, for indicated points and corresponding controls, as shown.

\section{Figure 7: The loss of Hsp90 association triggers EphB6 downregulation following ephrin-B2 stimulation.}

A) HEK-B6 cells were treated with eB2 for the indicated time periods, and EphB6 was immunoprecipitated with antiEphB6. Precipitates were analyzed for Hsp90 presence by Western-blotting with anti-Hsp90. EphB6 immunoprecipitation was confirmed by re-blotting with anti-EphB6. B) HEK-293 cells were plated on glass coverslips and transfected with EphB6-EGFP cDNA. Cells were cultured for $72 \mathrm{~h}$ and stimulated with eB2 for 20 min. Stimulated cells were fixed in $4 \%$ formaldehyde, permeabilized with $0.1 \%$ saponin, and stained with anti-Hsp90 and anti-rat Alexafluor-594 (red) labelled antibodies. Stained cells were visualized with an Olympus FV-1000 confocal microscope at 60X magnification. Images were deconvoluted using AutoQuant X3. Scale bar, $10 \mu \mathrm{m}$. The graph represents quantifications of colocalisation of EphB6 with Hsp90 using Pearson's correlation coefficient. Values were obtained from 3 independent experiments. ${ }^{* * *}, \mathrm{P}<2 \times 10^{-6}$. C) HEK-B6 cells were treated with $10 \mu \mathrm{g} / \mathrm{ml}$ of Hsp90 inhibitor, geldanamycin (GA) or the matching volume of solvent control (S.C.) for the indicated time periods. EphB6 levels were monitored by Western blotting with anti-EphB6. Results of Western blot quantification in GA-treated cells were normalized on Erk2 levels and presented in a graph as a percentage relative to matching solvent controls. D) HEK-B6 cells were treated with eB2 in the presence of the solvent control, or eB2 with GA, or with the solvent control alone, for the indicated time periods, and EphB6 levels were monitored by Western blotting. EphB6 levels in eB2-stimulated cells were normalized as in (C). Numbers representing this normalization are shown below Western blot images. Each graph in this figure summarises the analysis of three independent experiments, bars, SD. * $P<0.05$, Student's $\mathrm{t}$ test, between stimulated and control treated cells for the indicated time points. No statistically significant difference was observed between the rates of EphB6 downregulation in eB2 treated cells or GA treated cells, and cells cotreated with eB2 and GA at any time point measured. In all experiments involving eB2 stimulation, unstimulated cells were treated with hlgG as a specificity control. All Western blot and confocal microscopy images represent one of at least three independent experiments.

Figure 8: Proposed pathway of EphB6 ligand-induced downregulation. Prior to ligand binding, EphB6 is associated with Hsp90 at the cell membrane. Ligand-binding initiates EphB6 receptor clustering and Hsp90 dissociation. EphB6 is recruited into CCPs and endosomal vesicle formation is finalized by pinching off at the cell 
membrane by dynamin. Internalised EphB6 receptors are trafficked within Rab5-positive early endosomes, and are eventually targeted to the lysosomal compartment for degradation.

\section{Supplementary material}

Figure S1: EphB6 is targeted into lysosomes in response to ephrin-B2 stimulation. HEK-293 cells were seeded onto glass-bottomed plates, transfected with cDNA encoding an EphB6-EGFP fusion protein, and cultured for $72 \mathrm{~h}$. Cells were stained with 60 nM LysoTracker-Red DND99 for 30 min, washed twice with phenol red-free media, and stimulated at $37^{\circ} \mathrm{C}$ for the indicated time periods. Cells were visualized at $40 \mathrm{X}$ magnification with an Olympus FV 1000 confocal microscope prior to, and at each minute upon the addition of eB2 $(1 \mu \mathrm{g} / \mathrm{ml})$ for a total of 20 min. Images were deconvoluted using AutoQuant X3. Image represents one of three independent experiments.

Figure S2: EphB4 relocalises into lysosomes upon ephrin-B2 stimulation. HEK-293 cells expressing EphB4EGFP (HEK-B4-EGFP) were seeded, stained, treated, and visualized as in (Fig. S1). Image represents one of three independent experiments.

\section{Figure S3: Hsp90 colocalisation with EphB6 at the cell membrane is diminished following ephrin-B2}

treatment. HEK-293 cells were plated on glass coverslips and transfected with EphB6-EGFP cDNA. Cells were cultured for $72 \mathrm{~h}$ and stimulated with eB2 for $20 \mathrm{~min}$. Stimulated cells were fixed in $4 \%$ formaldehyde, permeabilised with $0.1 \%$ saponin, and stained with anti-Hsp90 and anti-rat Alexafluor-594 (red) labelled antibodies. Stained cells were visualized with an Olympus FV-1000 confocal microscope at 60X magnification. Images were deconvoluted using AutoQuant X3. Image represents one of three independent experiments.

\section{Movie S1: Hsp90 colocalises with EphB6 at the cell membrane. HEK-293 cells expressing EphB6-EGFP were} treated with hlgG for 20 min, fixed, permeabilised, and stained with anti-Hsp90 and Alexaflour-594-labelled anti-rat antibodies (red). Images were acquired with an Olympus FV-1000 confocal microscope using a 60X oil-immersion objective lens. Z-stack images were taken at $0.43 \mu \mathrm{m}$ intervals and the 3D representation was constructed using the Imaris software. Image represents one of three independent experiments.

All-red cell in the movie lacks EphB6-EGFP expression and represents a case of inefficient transfection. 
Movie S2: Ligand stimulation causes EphB6-Hsp90 dissociation. HEK-293 cell expressing EphB6-EGFP, were treated with eB2 for $20 \mathrm{~min}$, fixed, permeabilised, and stained with anti-Hsp90 and Alexaflour-594-labelled anti-rat antibodies (red). Images were acquired with an Olympus FV-1000 microscope using a 60X oil-immersion objective lens. Z-stack images were taken at $0.43 \mu \mathrm{m}$ intervals and the 3D representation was constructed using the Imaris software. Image represents one of three independent experiments. 
Allonby et al., Figure 1

C

A
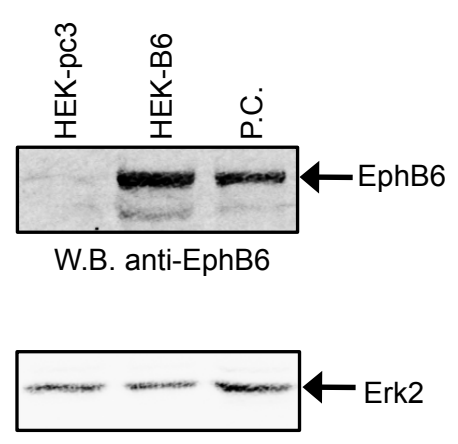

W.B. anti-Erk2

B
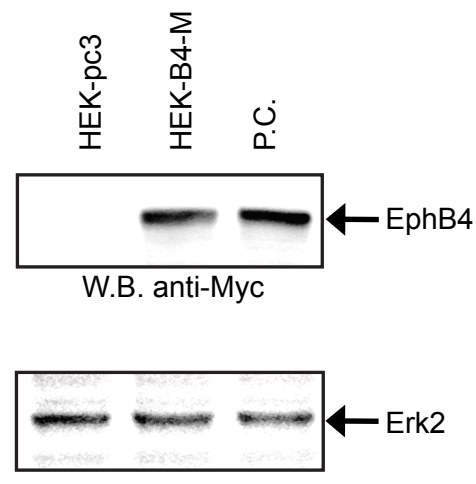

W.B. anti-Erk2
W.B. anti-EphB6

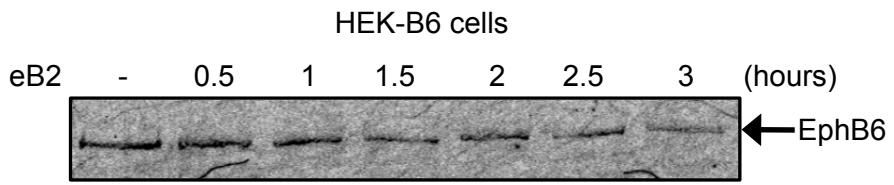

W.B. anti-EphB6

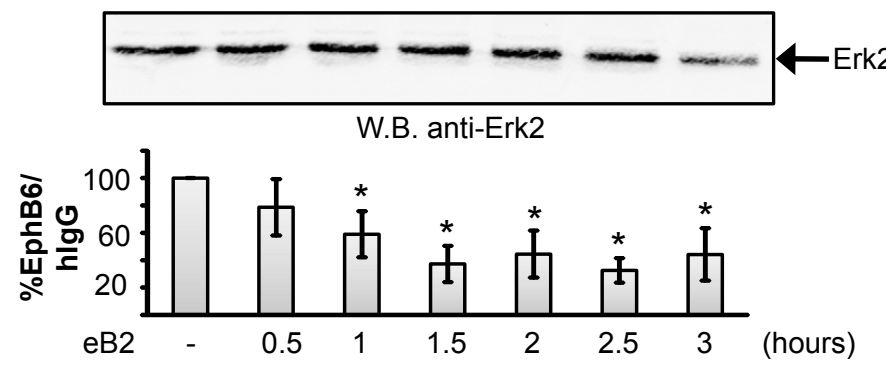

E

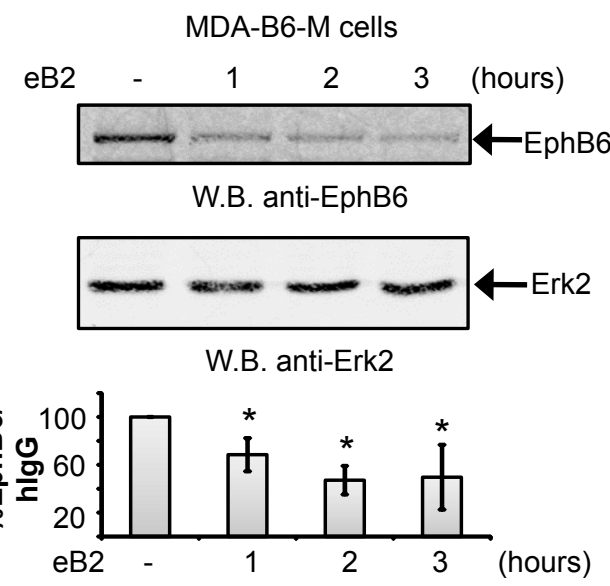

G

HCC-70 cells

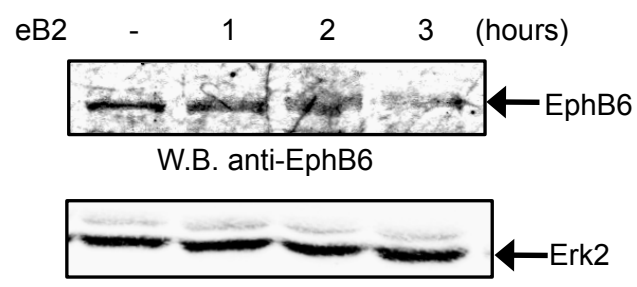

W.B. anti-Erk2

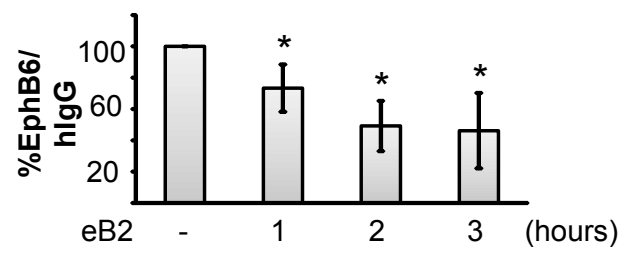

HEK-B4-M cells

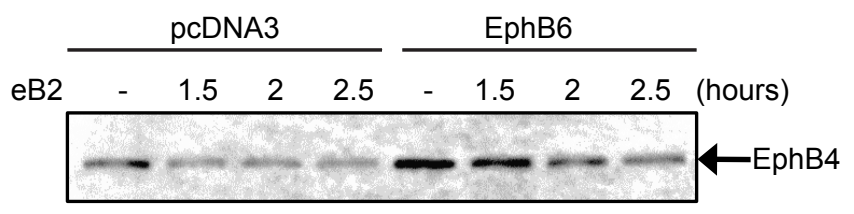

W.B. anti-Myc

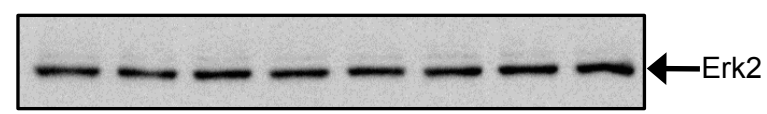

W.B. anti-Erk2

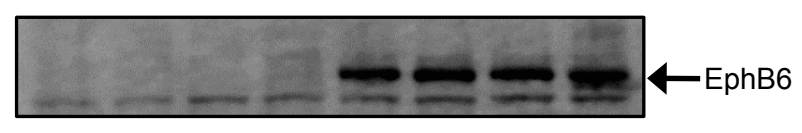

W.B. anti-EphB6

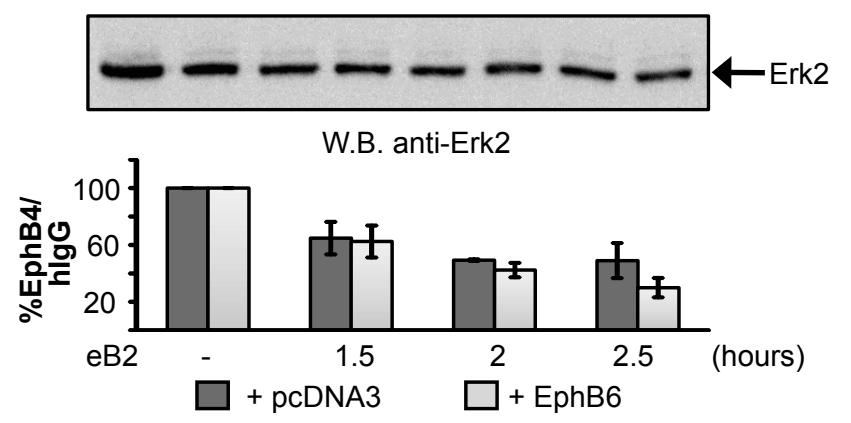


A

HEK-B6

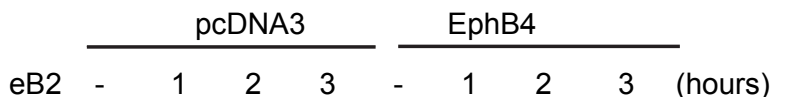

$-m-m-\infty-m-$ EphB6

W.B. anti-EphB6

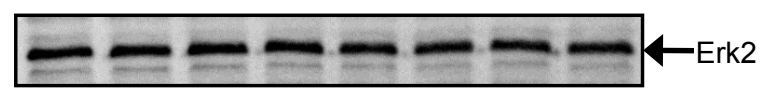

W.B. anti-Erk2

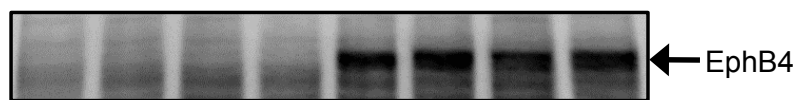

W.B. anti-Myc

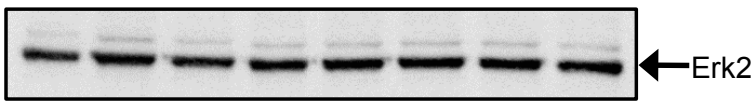

W.B. anti-Erk2

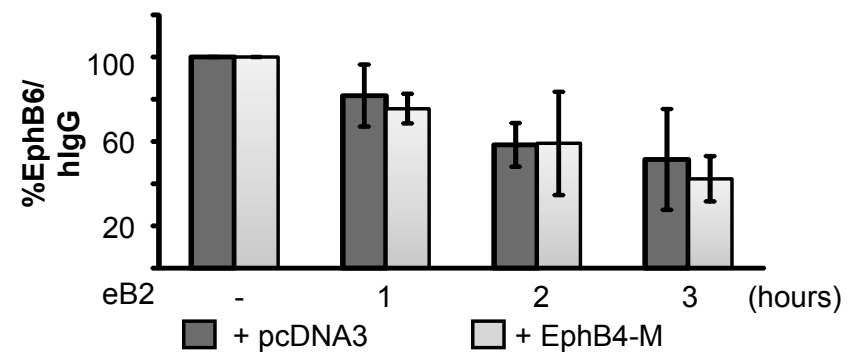

C

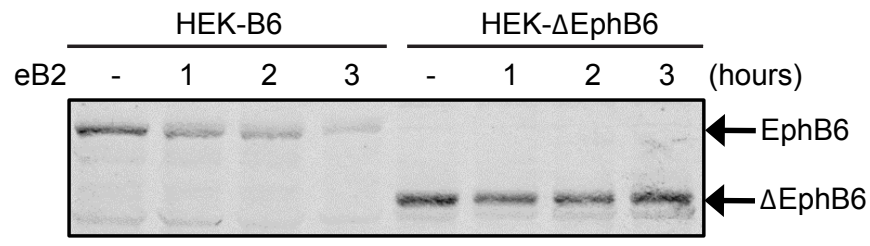

W.B. anti-EphB6

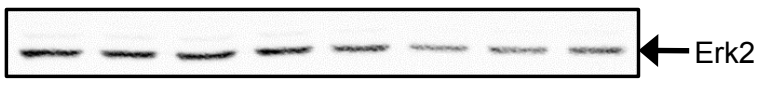

W.B. anti-Erk2

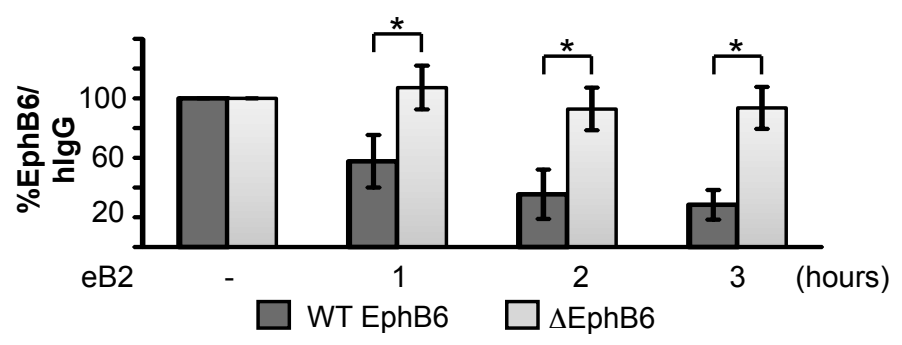

B

Allonby et al., Figure 2
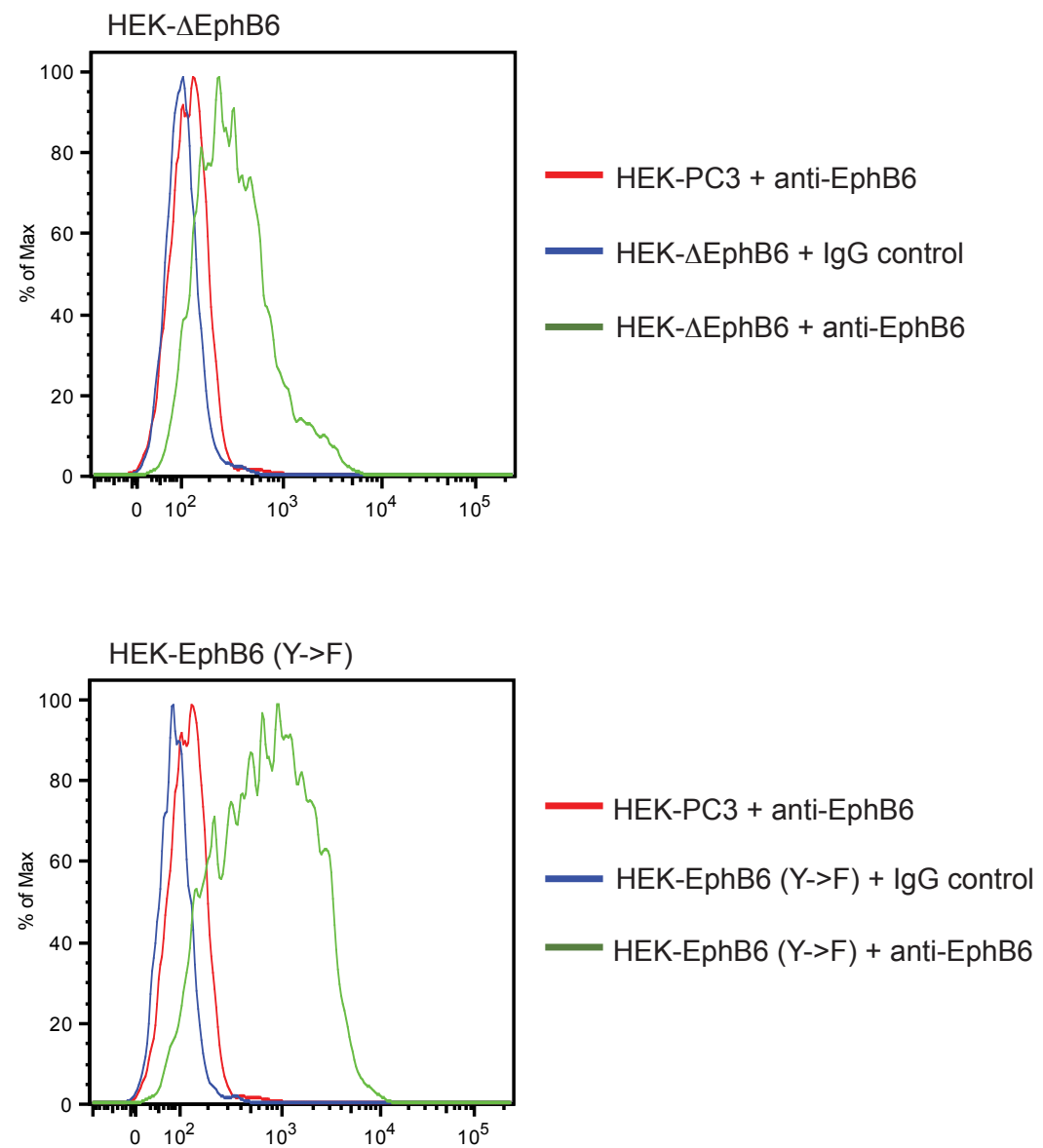

D

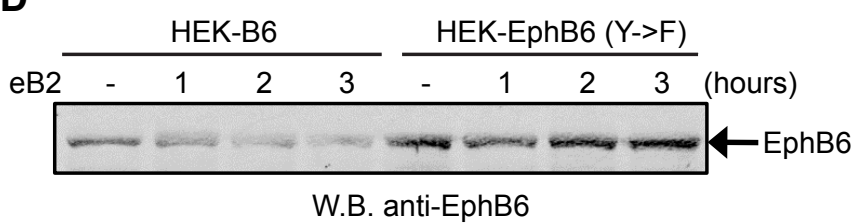

W.B. anti-EphB6

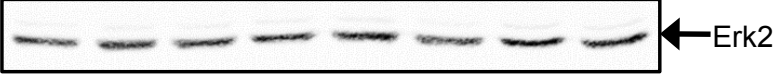

W.B. anti-Erk2

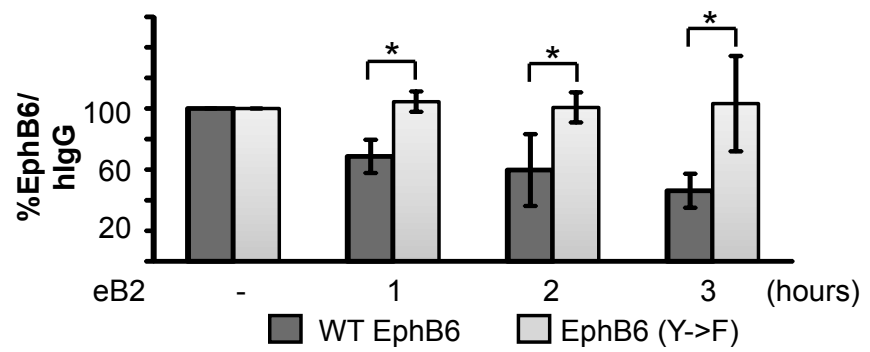


Allonby et al., Figure 3

A
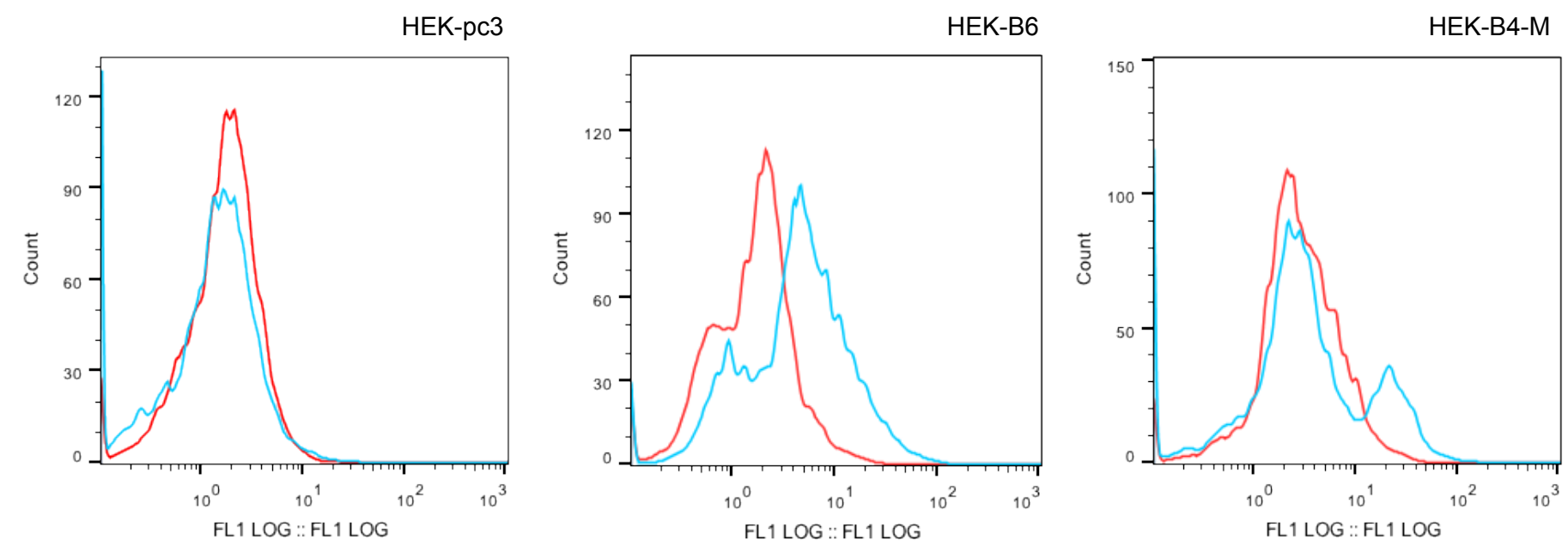

- Fixed

_ Fixed and Permeabilized

B
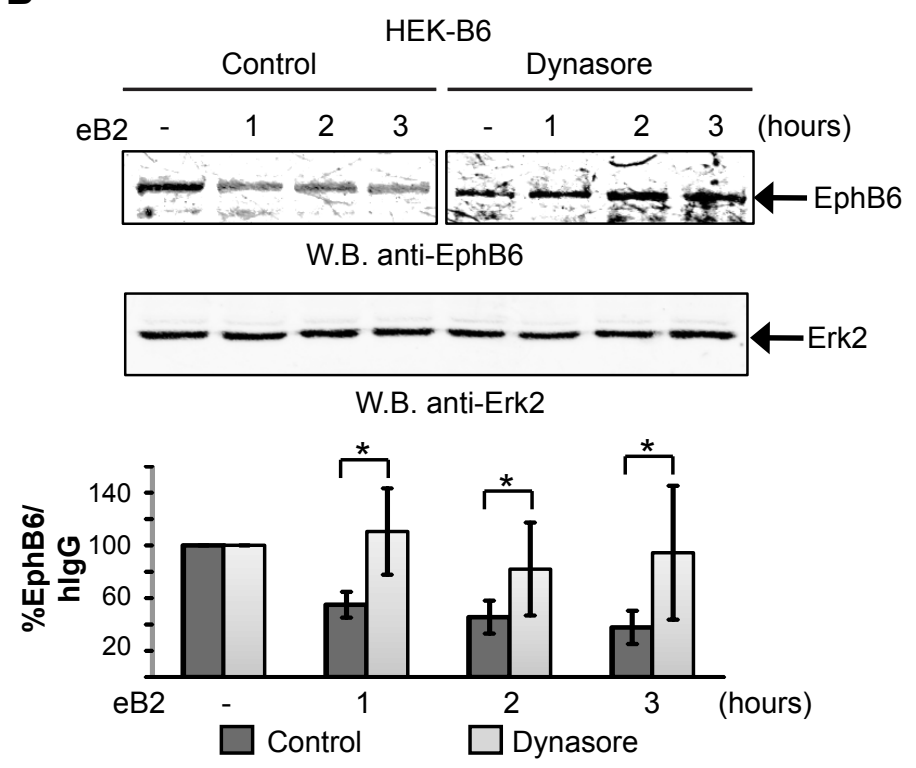

C
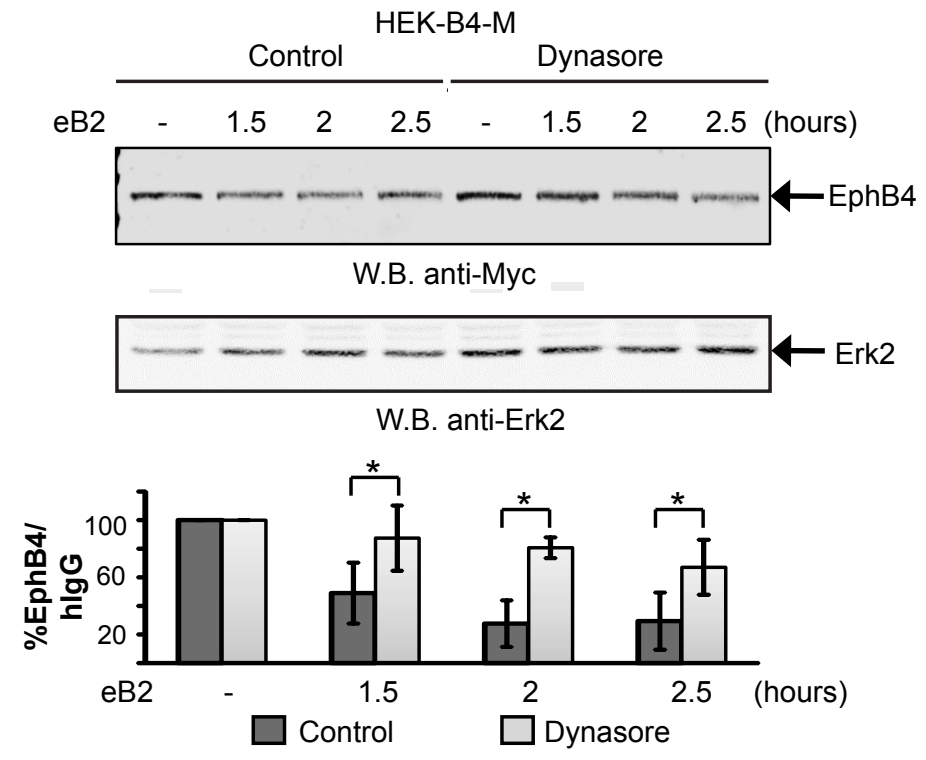
Odette et al., Figure 4

A
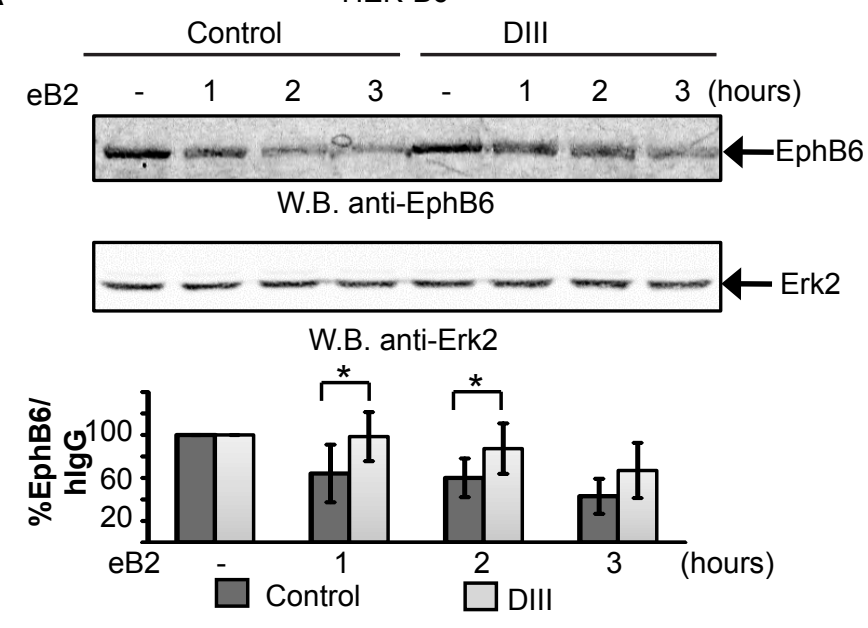

B

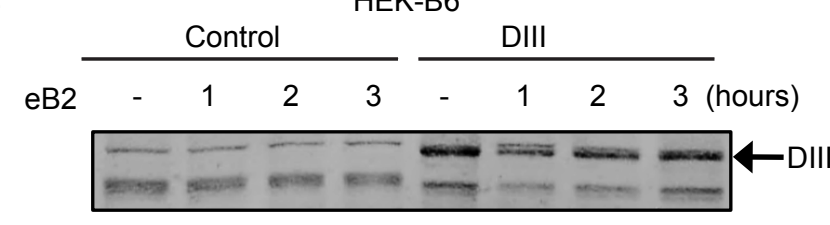

W.B. anti-Eps15

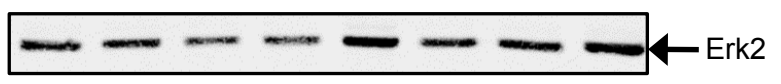

W.B. anti-Erk2

C

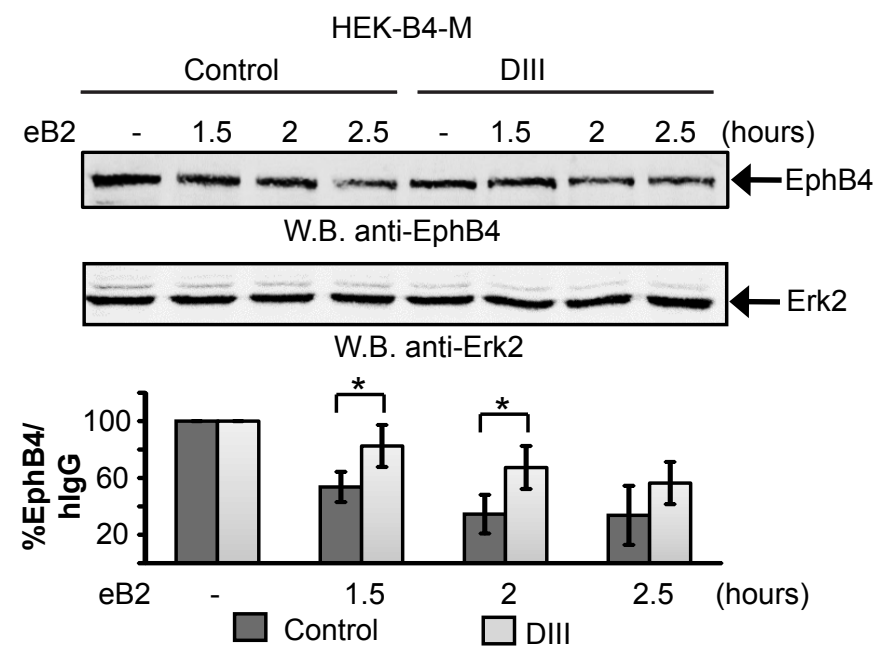

D

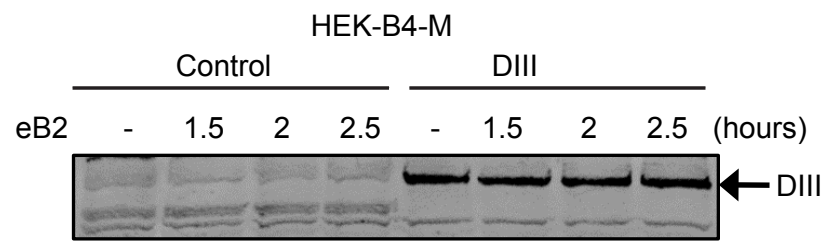

W.B. anti-Eps15

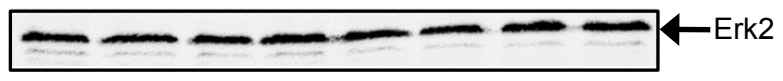

W.B. anti-Erk2
E

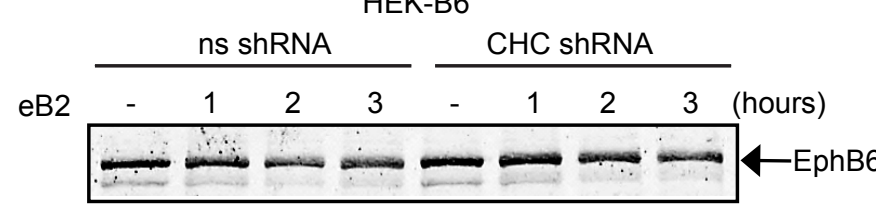

W.B. anti-EphB6

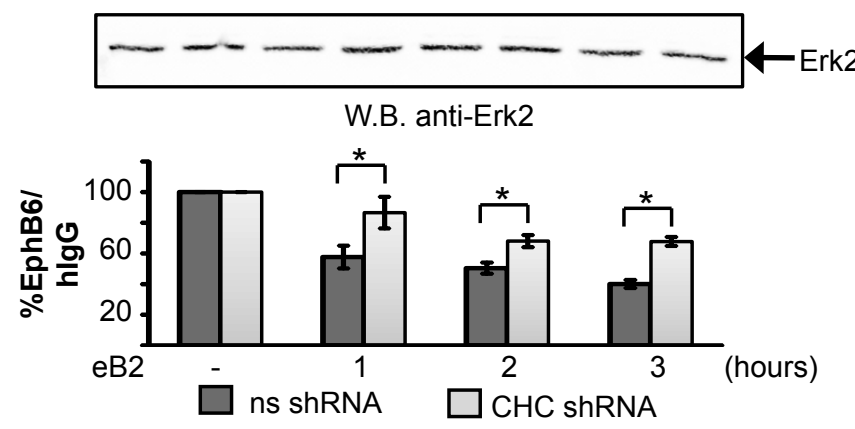

$\mathbf{F}$

HEK-B6

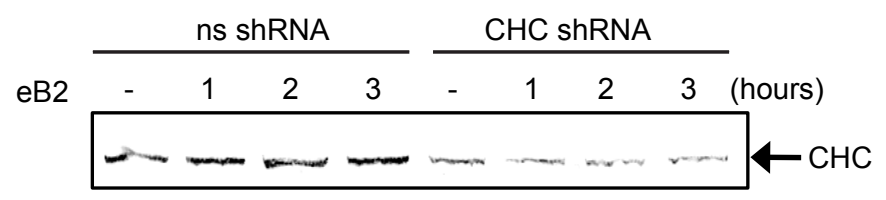

W.B. anti-CHC

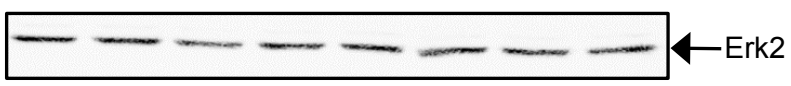

W.B. anti-Erk2

G

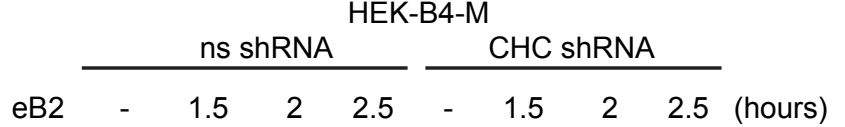
W.B. anti-EphB4

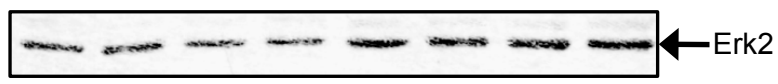
W.B. anti-Erk2

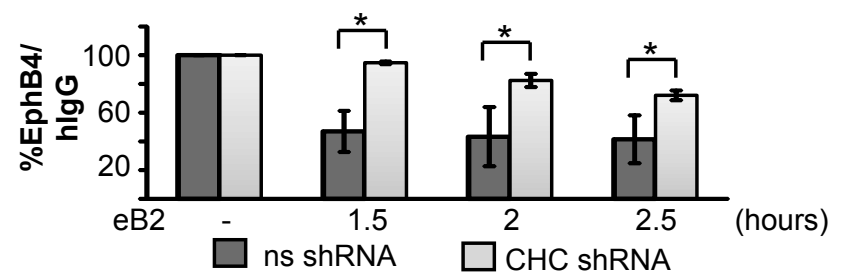

H HEK-B4-M

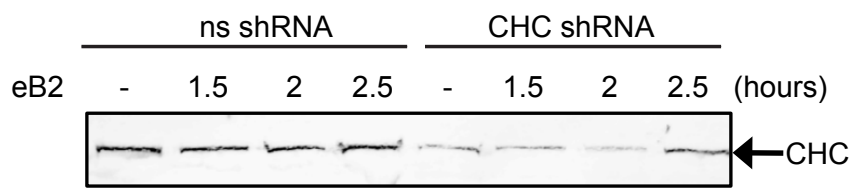
W.B. anti-CHC

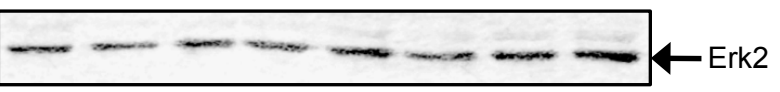

W.B. anti-Erk2 
A

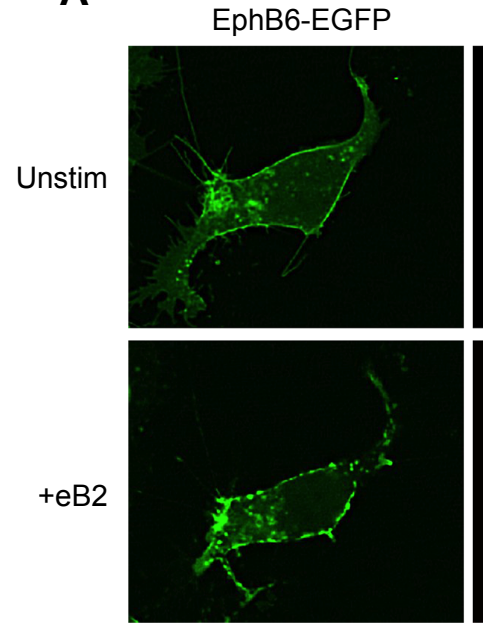

LysoTracker Red
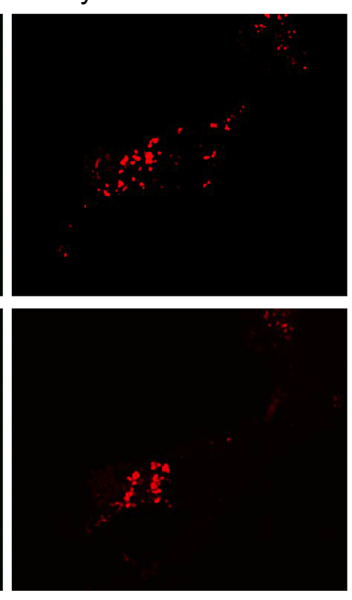

LysoTracker Red
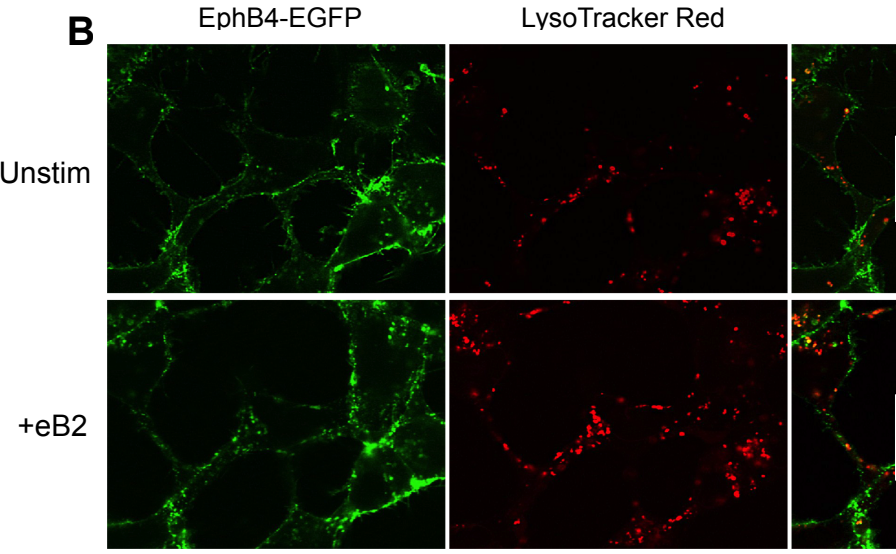

C

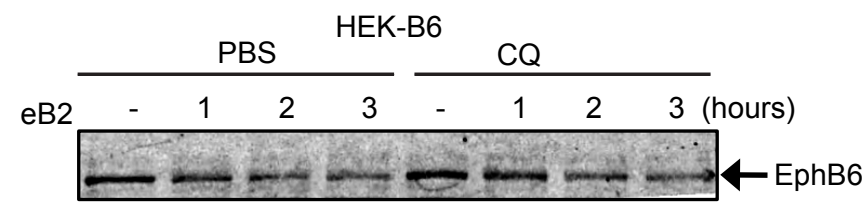

W.B. anti-EphB6

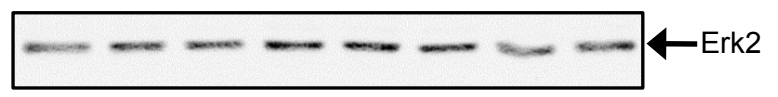

W.B. anti-Erk2

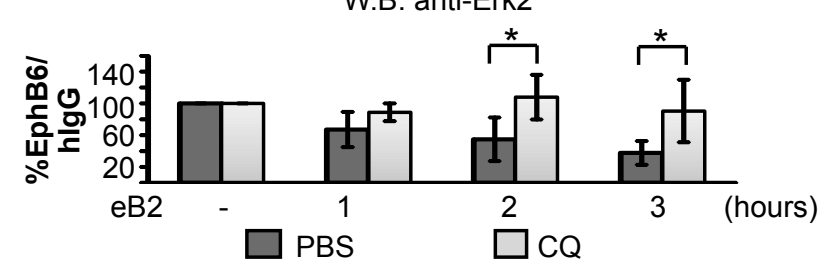

E

HEK-B6
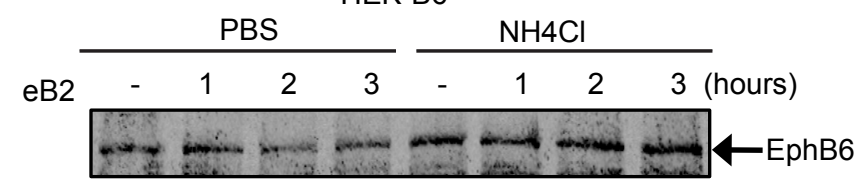

W.B. anti-EphB6

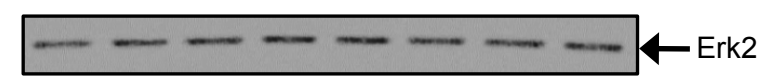

W.B. anti-Erk2

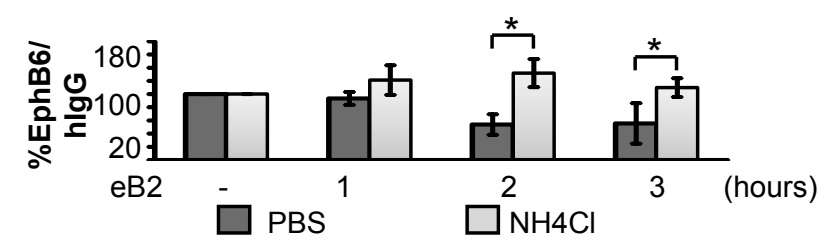

Merged

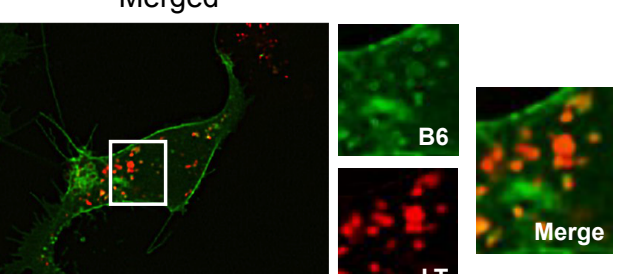

Merged
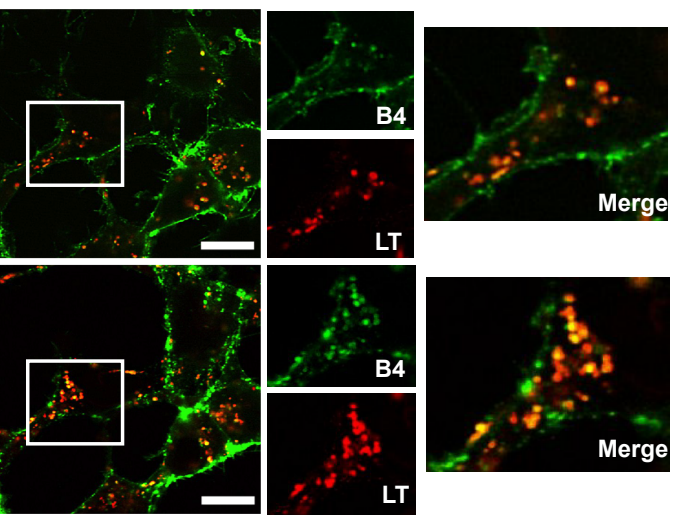

D
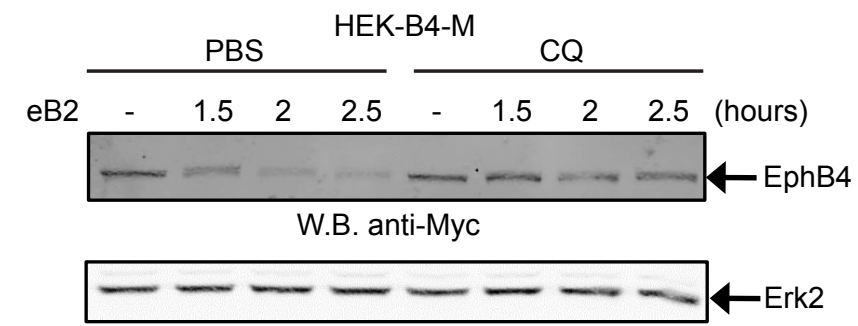

W.B. anti-Erk2

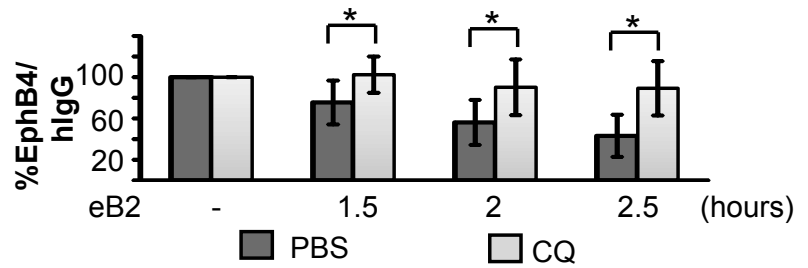

F
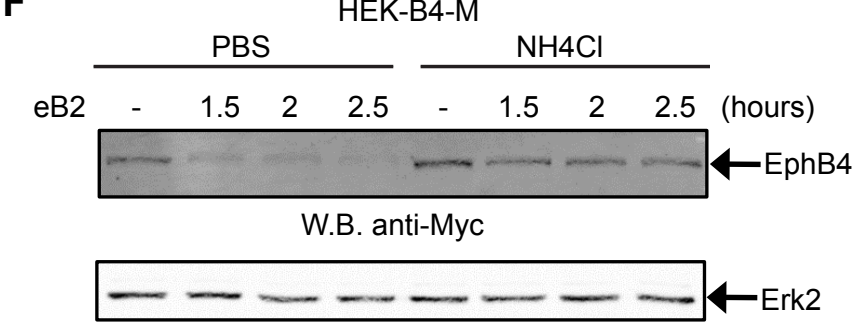

W.B. anti-Erk2

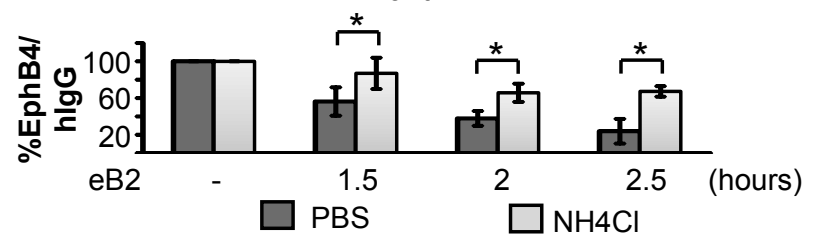


Allonby et al., Figure 6

A

HEK-B6

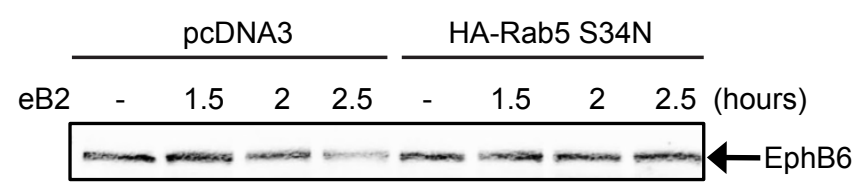

W.B. anti-EphB6

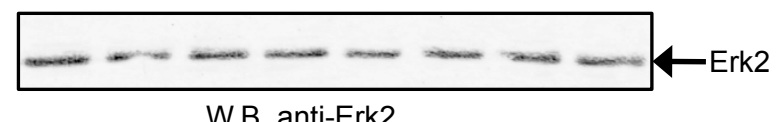

W.B. anti-Erk2
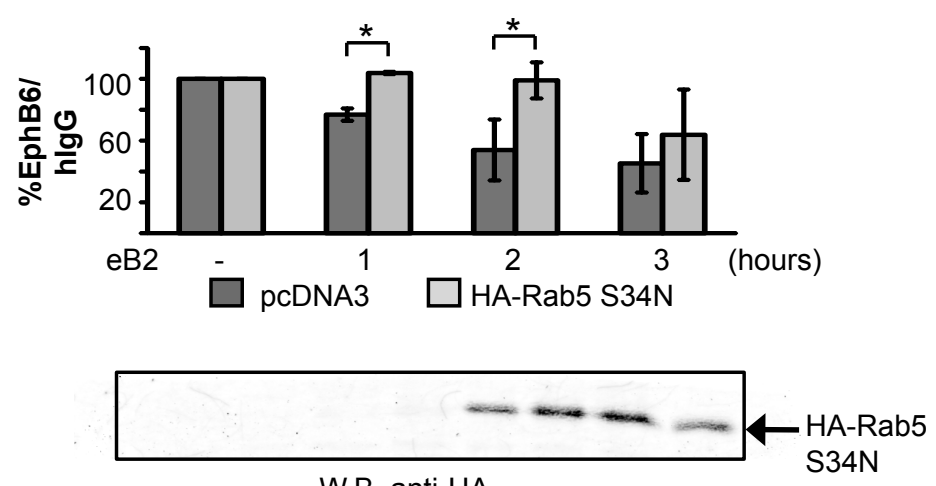

W.B. anti-HA

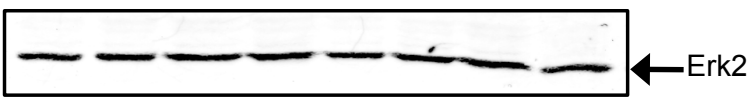

W.B. anti-Erk2
B

HEK-B4

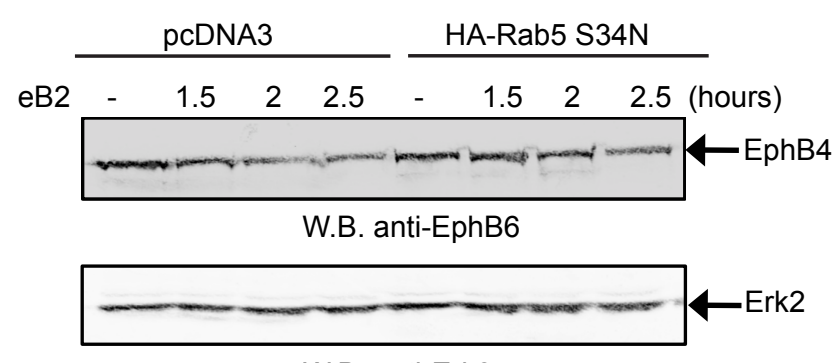

W.B. anti-Erk2
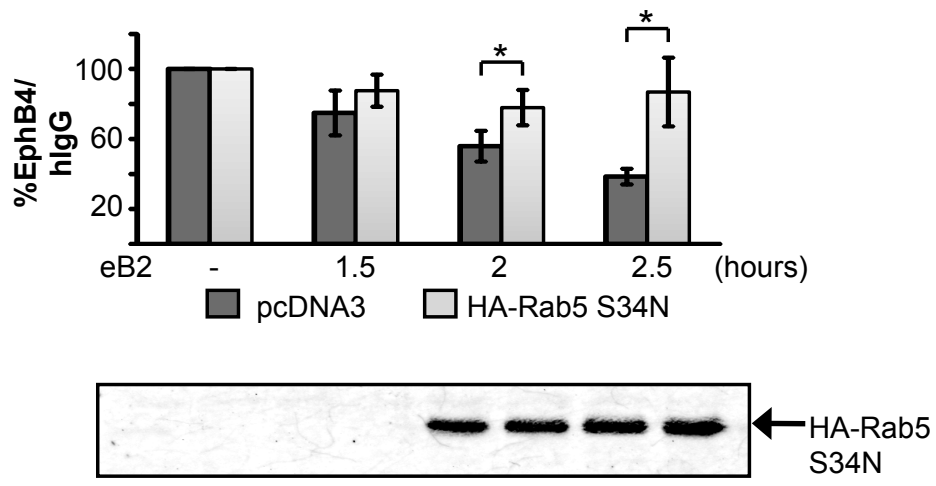

W.B. anti-HA

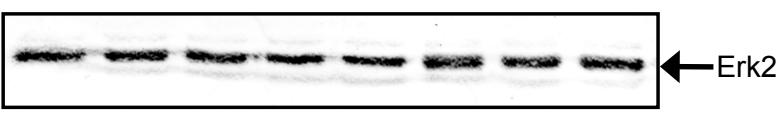

W.B. anti-Erk2 
A

HEK-B6

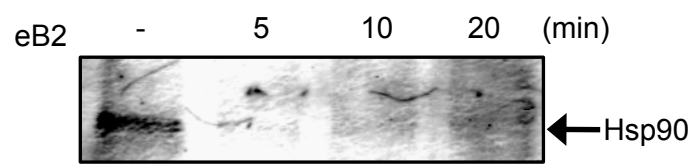

I.P. anti-EphB6 W.B. anti-Hsp90

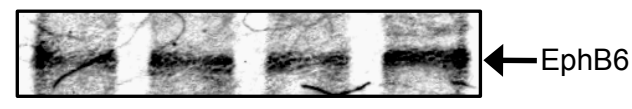

Reblot anti-EphB6
B

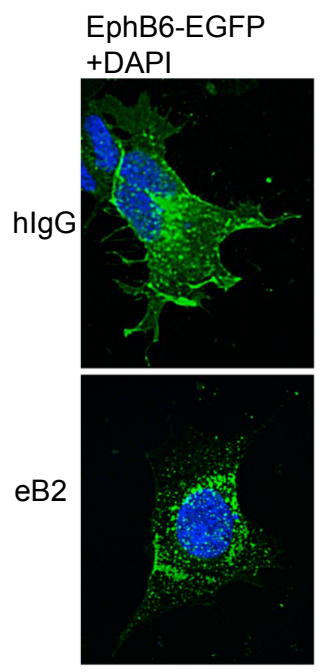

Allonby et al., Figure 7

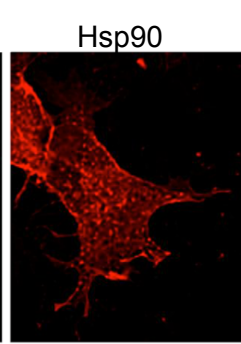

Merged

Merged

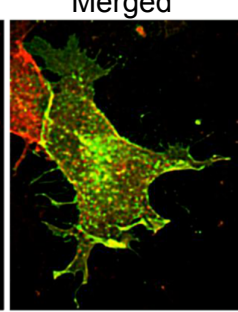
+DAPI
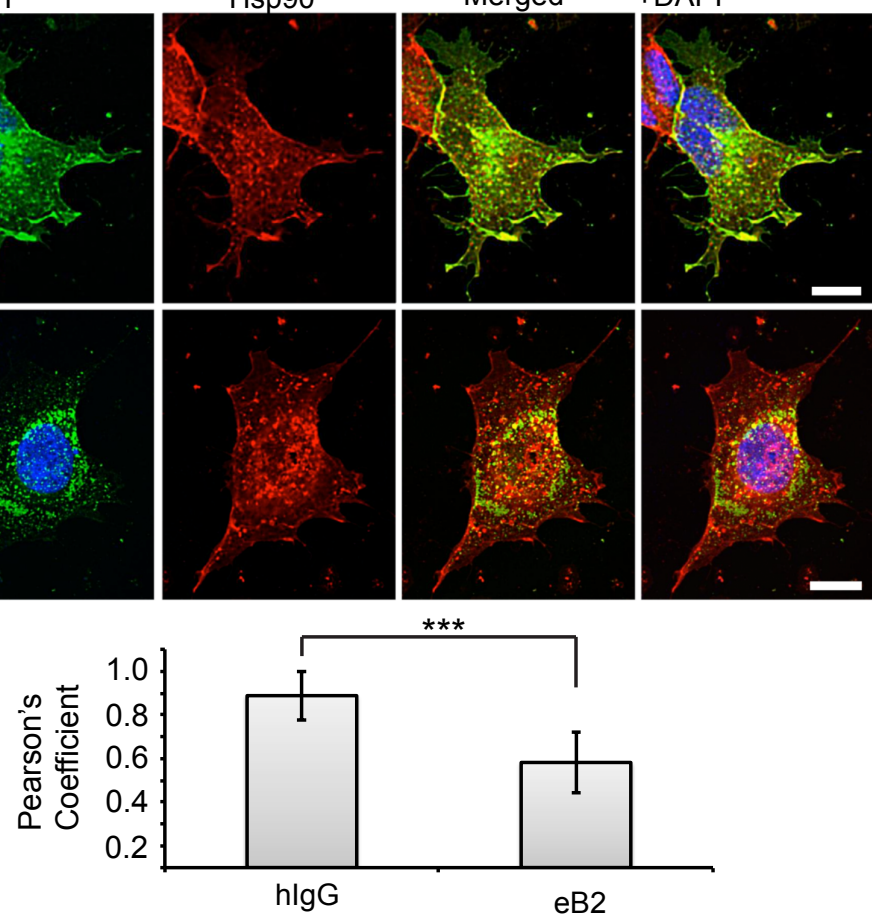

D HEK-B6

C

HEK-B6

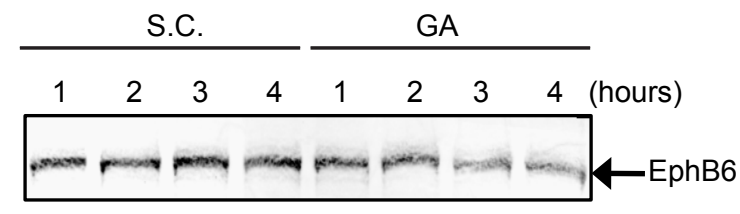

W.B. anti-EphB6

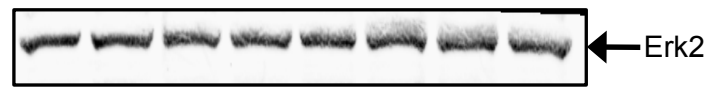

W.B. anti-Erk2

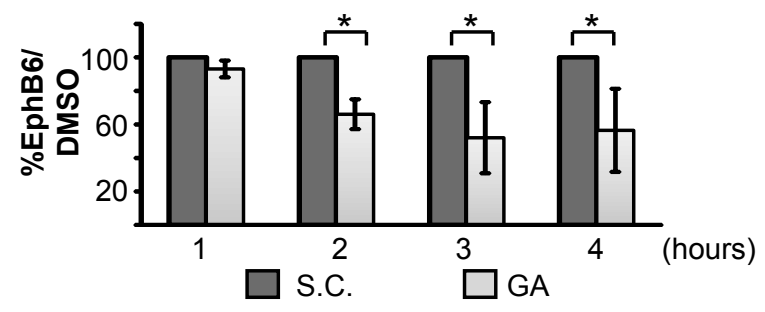

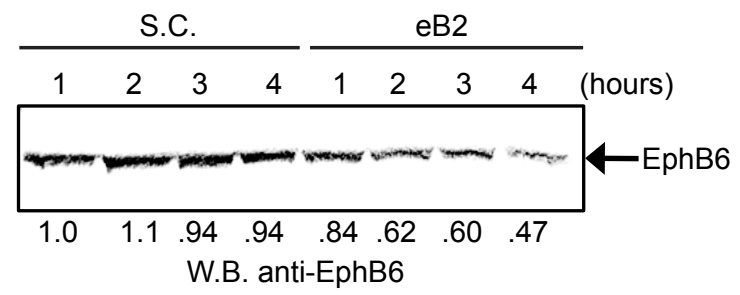

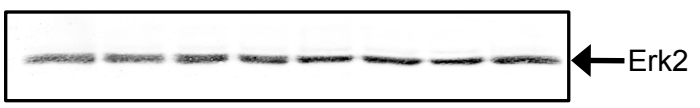

W.B. anti-Erk2
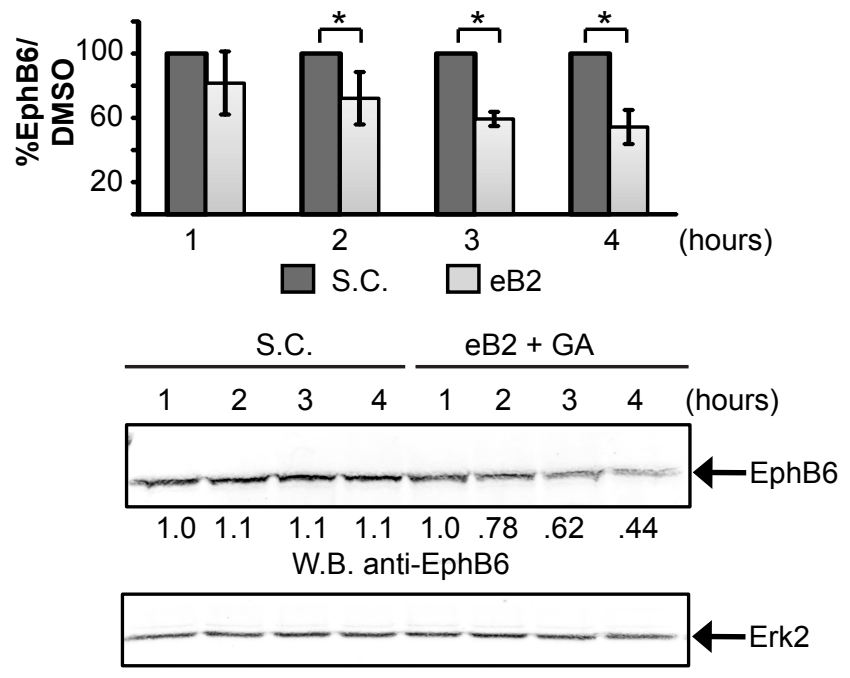

W.B. anti-Erk2

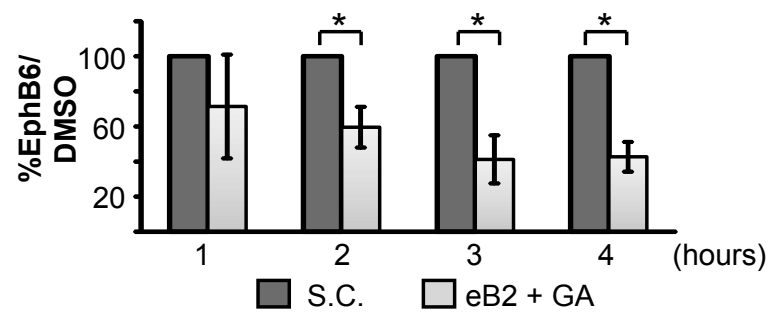


Allonby et al., Figure 8

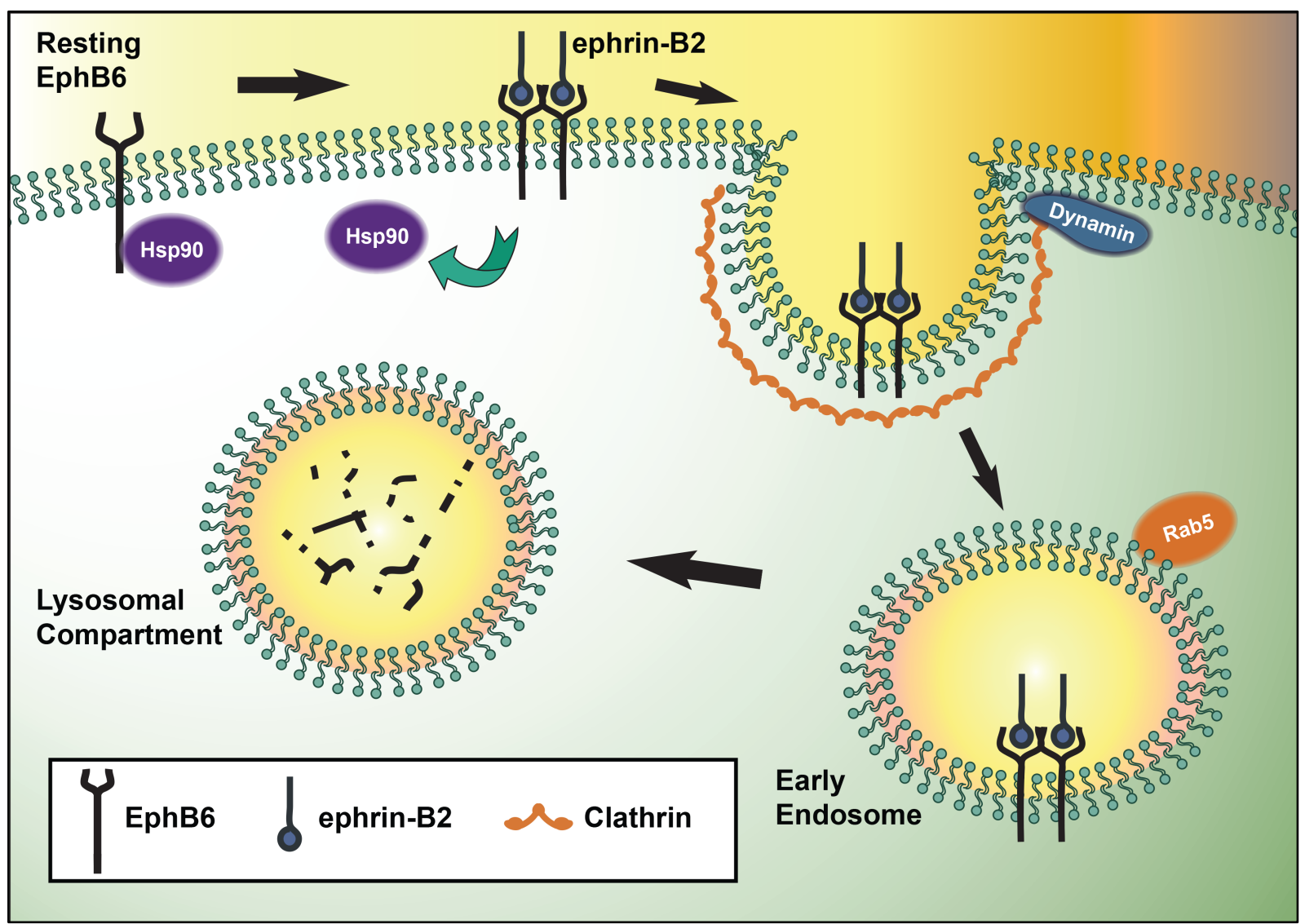


Allonby et al., Figure S1


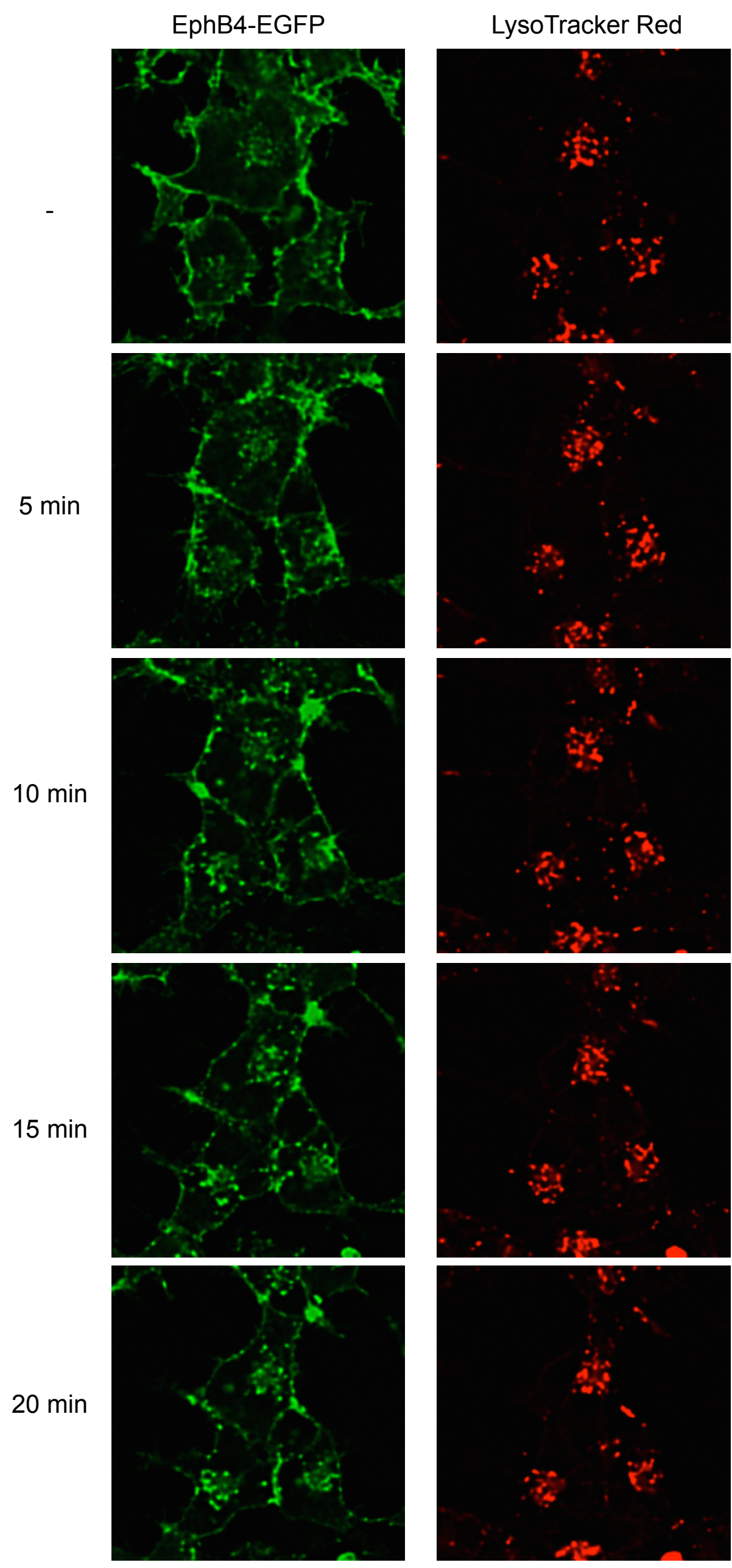

Allonby et al., Figure S2
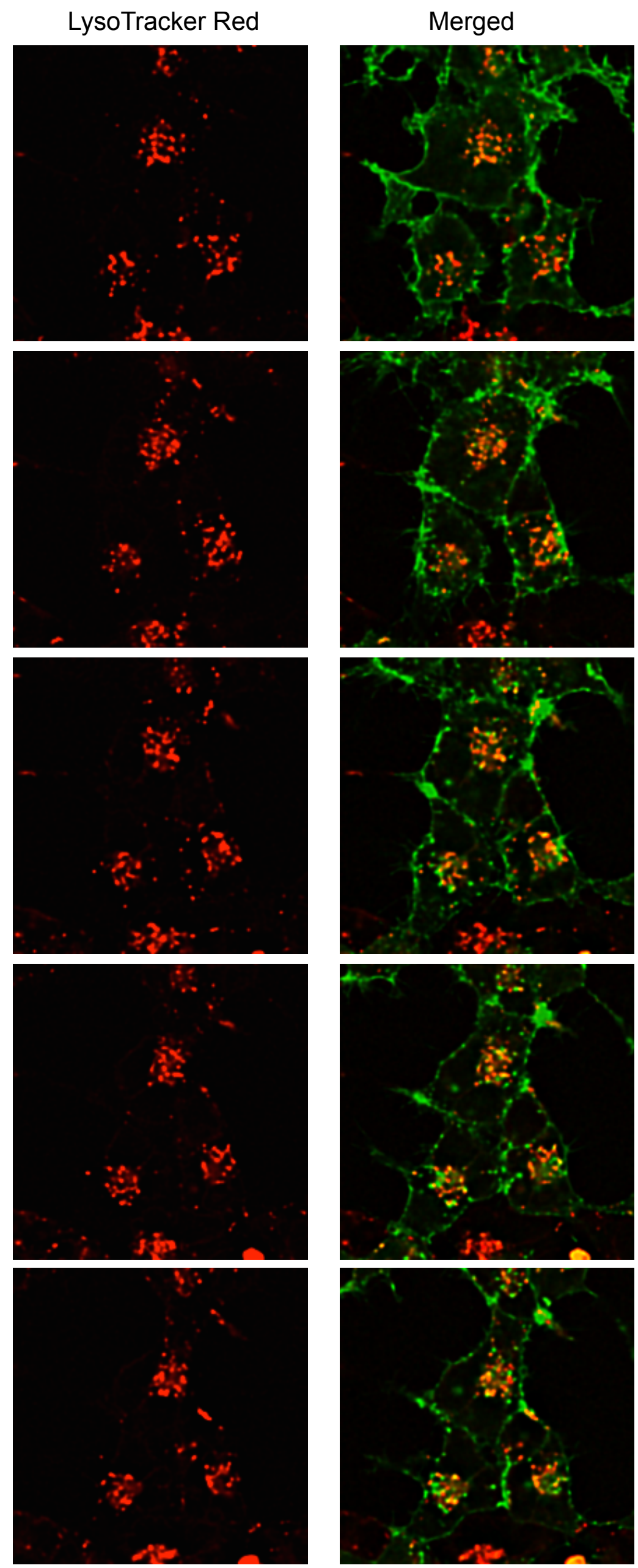
Allonby et al., Figure S3
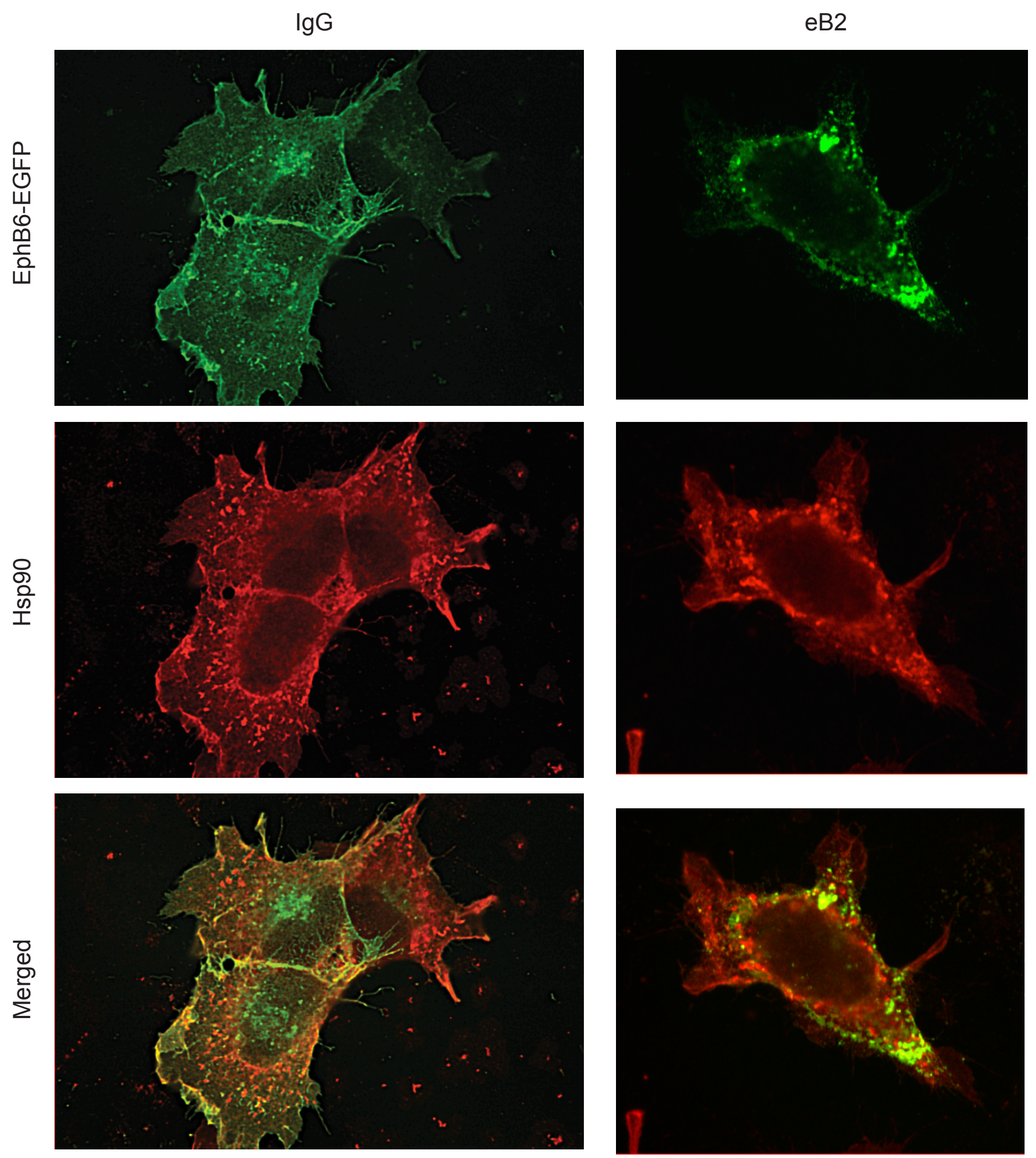


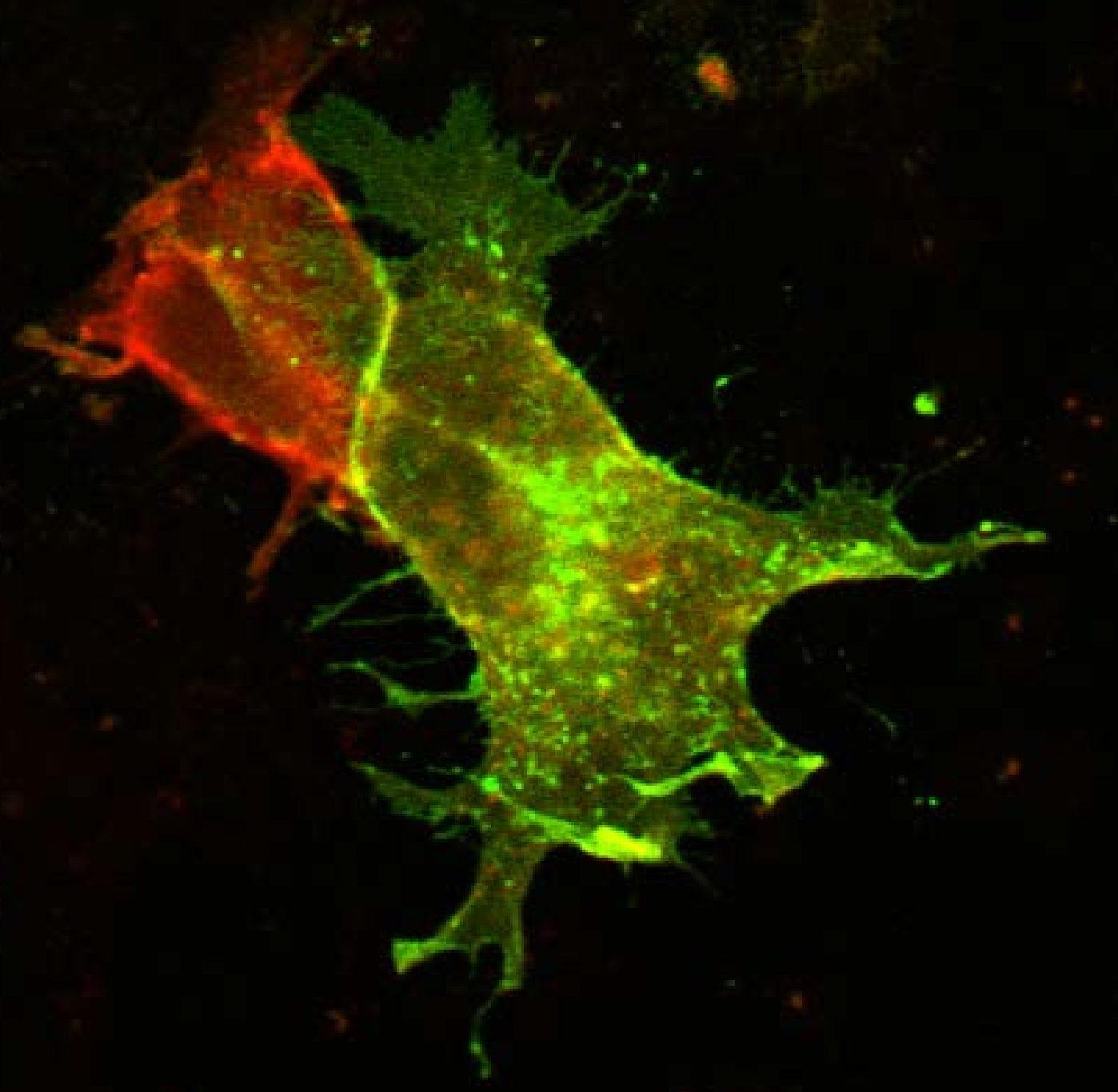


v 